NBER WORKING PAPER SERIES

\title{
THE GROWTH OF LOW SKILL SERVICE JOBS AND THE POLARIZATION OF THE U.S. LABOR MARKET
}

\author{
David H. Autor \\ David Dorn \\ Working Paper 15150 \\ http://www.nber.org/papers/w15150
NATIONAL BUREAU OF ECONOMIC RESEARCH
1050 Massachusetts Avenue
Cambridge, MA 02138
July 2009

We thank Daron Acemoglu, Joshua Angrist, Kerwin Charles, Luis Garicano, Maarten Goos, Caroline Hoxby, Lawrence Katz, Alan Manning, Matthias Weiss, and numerous seminar participants for excellent input that improved the paper. We thank Amanda Pallais and Jessica Pan for superb research assistance, and Mark Doms and Ethan Lewis for generous assistance with data. We are deeply indebted to Rachel Ngai and Alp Simsek for assistance with the theoretical model. Autor acknowledges support from the National Science Foundation (CAREER award SES-0239538). Dorn acknowledges funding from the Swiss National Science Foundation. The views expressed herein are those of the author(s) and do not necessarily reflect the views of the National Bureau of Economic Research.

NBER working papers are circulated for discussion and comment purposes. They have not been peerreviewed or been subject to the review by the NBER Board of Directors that accompanies official NBER publications.

(C) 2009 by David H. Autor and David Dorn. All rights reserved. Short sections of text, not to exceed two paragraphs, may be quoted without explicit permission provided that full credit, including $\mathbb{C}$ notice, is given to the source. 
The Growth of Low Skill Service Jobs and the Polarization of the U.S. Labor Market

David H. Autor and David Dorn

NBER Working Paper No. 15150

July 2009, Revised May 2012

JEL No. E24,J24,J31,J62,O33

\begin{abstract}
$\underline{\text { ABSTRACT }}$
We offer an integrated explanation and empirical analysis of the polarization of U.S. employment and wages between 1980 and 2005, and the concurrent growth of low skill service occupations. We attribute polarization to the interaction between consumer preferences, which favor variety over specialization, and the falling cost of automating routine, codifiable job tasks. Applying a spatial equilibrium model, we derive, test, and confirm four implications of this hypothesis. Local labor markets that were specialized in routine activities differentially adopted information technology, reallocated low skill labor into service occupations (employment polarization), experienced earnings growth at the tails of the distribution (wage polarization), and received inflows of skilled labor.
\end{abstract}

David H. Autor

Department of Economics

MIT, E52-371

50 Memorial Drive

Cambridge, MA 02142-1347

and NBER

dautor@mit.edu

David Dorn

David Dorn

CEMFI

Casado del Alisal 5

28014 Madrid

Spain

dorn@cemfi.es 
A vast literature documents a pronounced rise in wage inequality in the United States and numerous other advanced nations commencing in the 1980s and proposes skill-biased technological change as its primary cause. The intellectual foundation of this literature is what Acemoglu and Autor (2010) refer to as the canonical model, which features two distinct skill groups - typically, college and high-school workers - performing two distinct and imperfectly substitutable occupations or producing two imperfectly substitutable goods. ${ }^{1}$ Technology in the canonical model is assumed to take a factor-augmenting form, meaning that it complements either high or low skill workers and thus induces either a monotone increase or decrease in wage inequality between skill groups. The canonical model is not only tractable and conceptually attractive but has also proved empirically quite successful in accounting for the evolution of skill premia in the United States throughout the twentieth century, as well as capturing major cross-country differences in skill premia among advanced nations. ${ }^{2}$

Despite its virtues, the canonical model falls short of providing a satisfactory framework for understanding two major features of the recent evolution of inequality that are the focus of this paper. A first is the strikingly non-monotone growth of employment by skill level, which is depicted in Figure 1a. This figure is constructed by using Census IPUMS and American Community Survey (ACS) data to calculate the change between 1980 and 2005 in the share of employment accounted for by 318 detailed occupations encompassing all of U.S. non-farm employment. Occupations are ranked by skill level, which is approximated by the mean log wage of workers in each occupation in 1980.

Consistent with the conventional view of skill-biased technological change, employment growth is differentially rapid in occupations in the upper two skill quartiles. More surprising in light of the canonical model are the employment shifts seen below the median skill level. While occupations in the second skill quartile fell as a share of employment, those in the lowest skill quartile expanded sharply. In net, employment changes in the U.S. during this period were strongly U-shaped in skill level, with relative employment declines in the middle of the distribution and relative gains at the tails. Notably, this pattern of employment polarization is not unique to the U.S. Although not recognized until recently, a similar 'polarization' of employment by skill level has been underway in numerous industrialized economies in the last twenty to thirty years. ${ }^{3}$

The second key unexplained feature of the evolution of inequality on which we focus is the non-monotonicity of wage changes by skill percentile in this same period (Figure 1b). As with employment growth, wage growth is strikingly U-shaped in skill percentiles, with the greatest gains

\footnotetext{
${ }^{1}$ In many cases, this model is extended to more than two skill groups (see, e.g., Card and Lemieux, 2001, and Acemoglu, Autor and Lyle, 2004).

${ }^{2}$ See Katz and Murphy (1992) and a large subsequent literature summarized and extended by Katz and Autor (1999), Acemoglu (2002), Goldin and Katz (2008) and Acemoglu and Autor (2010).

${ }^{3}$ Using harmonized European Union Labour Force Survey Data, Goos, Manning and Salomons (2009, 2010) find that in 15 of 16 European countries for which data are available, high-paying occupations expanded relative to middle-wage occupations in the 1990s and 2000s, and in all 16 countries, low-paying occupations expanded relative to middle-wage occupations. The polarization of U.S. employment was initially studied by Acemoglu (1999). Goos and Manning (2007) provided the first rigorous analysis of polarization based on U.K. data.
} 

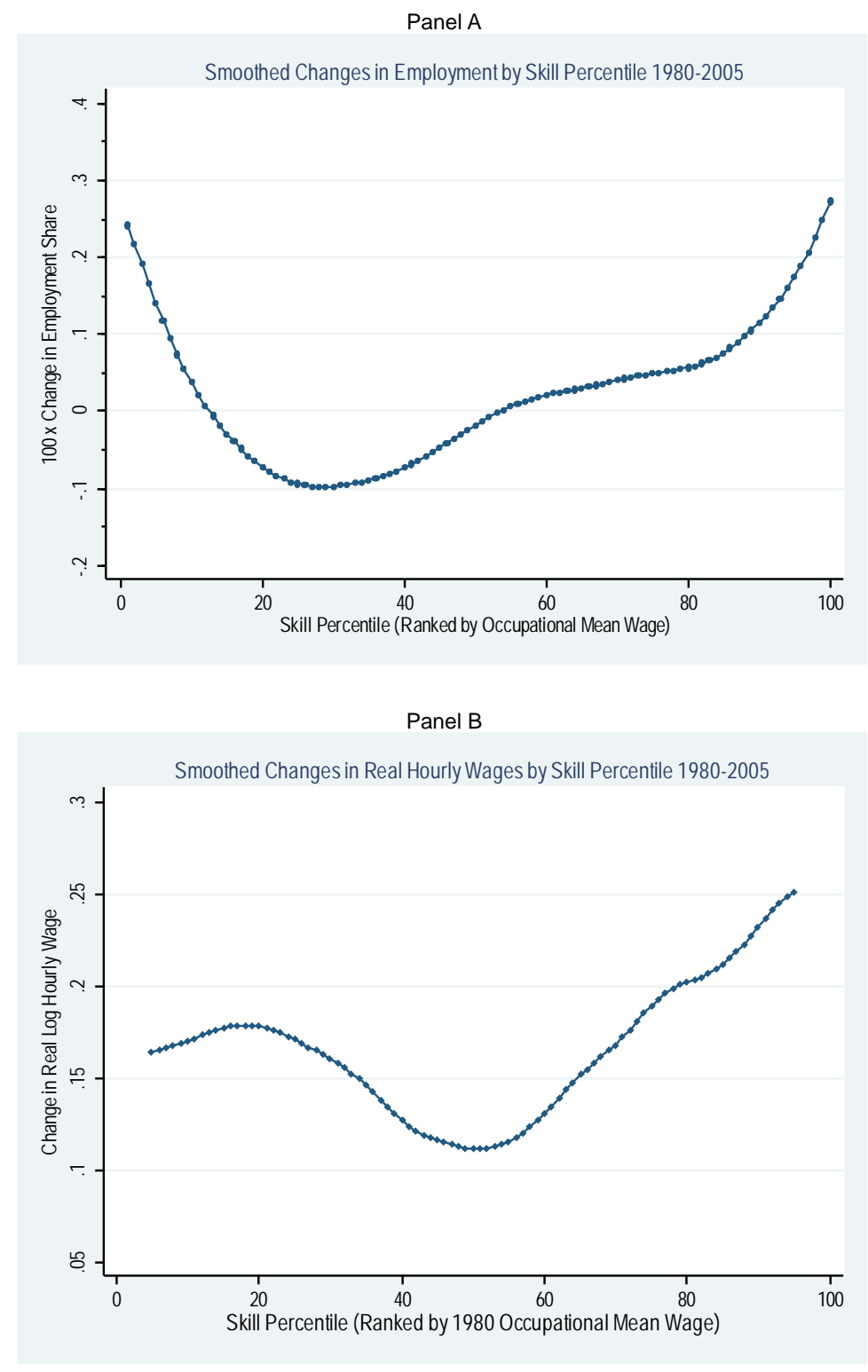

Figure 1.

Smoothed Changes in Employment (Panel A) and Hourly Wages (Panel B) by Skill Percentile, 1980-2005.

in the upper tail, modest gains in the lower tail, and substantially smaller gains towards the median. ${ }^{4}$

This paper offers an integrated explanation and detailed empirical analysis of the forces behind the changing shape of low education, low wage employment in the U.S. labor market. A first contribution of the paper is to document a hitherto unknown fact. The twisting of the lower tail of the employment and earnings distributions is substantially accounted for by rising employment and

\footnotetext{
${ }^{4}$ Figures 1a and $1 \mathrm{~b}$ use the same run variable on the x-axis (1980 occupational rankings and employment shares) and are therefore directly comparable. The polarization plots in Figure 1a and $1 \mathrm{~b}$ differ from related analyses in Autor, Katz and Kearney (2006 and 2008), Acemoglu and Autor (2010) and Firpo, Fortin and Lemieux (2011), which use occupational skill percentiles to measure employment polarization and use raw wage percentiles to measure wage polarization.
} 
Table 1. Levels and Changes in Employment Share and Mean Real Log Hourly Wages by Major Occupation Groups, 1950-2005: Occupations Ordered by Average Wage Level

\begin{tabular}{|c|c|c|c|c|c|c|c|c|}
\hline \multirow[b]{4}{*}{ Managers/Prof/Tech/Finance/Public Safety } & \multicolumn{6}{|c|}{ Level } & \multicolumn{2}{|c|}{$\begin{array}{c}\% \text { Growth / } \\
\text { (Growth per 10yrs) }\end{array}$} \\
\hline & 1950 & 1970 & 1980 & 1990 & 2000 & 2005 & $1950-80$ & $1980-05$ \\
\hline & \multicolumn{8}{|c|}{ A. Share of Employment } \\
\hline & 22.3 & 25.8 & 31.6 & 38.2 & 39.6 & 40.9 & $41(13.8)$ & $30(11.9)$ \\
\hline Production/Craft & 5.1 & 4.8 & 4.8 & 3.5 & 3.6 & 3.0 & $-5(-1.8)$ & $-38(-15.1)$ \\
\hline Transport/Construct/Mech/Mining/Farm & 29.2 & 22.3 & 21.6 & 18.8 & 18.0 & 18.2 & $-26(-8.7)$ & $-15(-6.2)$ \\
\hline Machine Operators/Assemblers & 12.6 & 13.2 & 9.9 & 7.3 & 5.7 & 4.6 & $-21(-7.0)$ & $-54(-21.5)$ \\
\hline Clerical/Retail Sales & 20.2 & 23.2 & 22.2 & 21.7 & 21.4 & 20.4 & $10(3.4)$ & $-8(-3.3)$ \\
\hline \multirow[t]{2}{*}{ Service Occupations } & 10.7 & 10.7 & 9.9 & 10.5 & 11.6 & 12.9 & $-7(-2.3)$ & $30(11.9)$ \\
\hline & \multicolumn{8}{|c|}{ B. Mean Log Hourly Wage $(2004 \$)$} \\
\hline Managers/Prof/Tech/Finance/Public Safety & 2.20 & 2.86 & 2.83 & 2.89 & 3.02 & 3.13 & $63(20.9)$ & $30(12.1)$ \\
\hline Production/Craft & 2.26 & 2.75 & 2.76 & 2.73 & 2.70 & 2.72 & $50(16.6)$ & $-4(-1.4)$ \\
\hline Transport/Construct/Mech/Mining/Farm & 2.04 & 2.56 & 2.61 & 2.56 & 2.63 & 2.63 & $56(18.8)$ & $3(1.1)$ \\
\hline Machine Operators/Assemblers & 2.04 & 2.46 & 2.48 & 2.46 & 2.52 & 2.54 & $44(14.7)$ & $6(2.3)$ \\
\hline Clerical/Retail Sales & 2.00 & 2.44 & 2.42 & 2.45 & 2.55 & 2.60 & $42(14.1)$ & $18(7.2)$ \\
\hline Service Occupations & 1.47 & 2.02 & 2.10 & 2.14 & 2.25 & 2.26 & $63(21.1)$ & $16(6.4)$ \\
\hline
\end{tabular}

wages in a single broad category of employment: service occupations.

Service occupations are jobs that involve assisting or caring for others, for example, food service workers, security guards, janitors and gardeners, cleaners, home health aides, child care workers, hairdressers and beauticians, and recreation occupations. ${ }^{5}$ Though among the least educated and lowest paid categories of employment, the share of U.S. labor hours in service occupations grew by 30 percent between 1980 and 2005 after having been flat or declining in the three prior decades (Table 1). This rapid growth stands in contrast to declining employment in all similarly low-educated occupation groups, which include production and craft occupations, operative and assembler occupations, and transportation, construction, mechanical, mining and farm occupations. The increase was even steeper among non-college workers, by which we mean those with no more than a high school education, among whom service occupation employment rose from 12.9 to 19.8 percent of total work hours between 1980 and 2005, a 53 percent increase (Appendix Table 1). Accompanying their rising employment, real wage growth in service occupations substantially outpaced that in other low skill occupations, averaging 6.4 percent per decade between 1980 and 2005.

\footnotetext{
${ }^{5}$ It is critical to distinguish service occupations, a group of low-education occupations providing personal services and comprising 14.3 percent of labor input in 2005 (Table 1), from the service sector, a broad category of industries ranging from health care to communications to real estate and comprising 83 percent of non-farm employment in 2005 (source: www.bls.gov). Since part-time jobs are relatively prevalent in service occupations, the share of service jobs in U.S. employment is even larger than their share in total labor input. Hecker (2005) reports that service occupations accounted for nearly one in five jobs in 2004, whereas our calculations in Table 1 find that service occupations contribute approximately one in seven hours of labor input.
} 
Figure 2 highlights the contribution of service occupations to aggregate employment and wage polarization by calculating a simple counterfactual scenario in which employment and wages in service occupations are held at their 1980 level. The upper panel of Figure 2 shows that reweighting the distribution of employment in 2005 to hold the share of employment in service occupations constant at its 1980 level substantially reduces the upward twist of the lower tail of the employment distribution during this twenty-five year period. ${ }^{6}$ Similarly, holding the real wage levels of service occupations at their 1980 level throughout the 1980 through 2005 period (panel B) substantially dampens the upward twist of the lefthand tail of the distribution of wage changes by occupational skill in this time interval.

While the rapid growth of low-wage, low-education service occupations since 1980 may appear inconsistent with the conventional narrative in which low-skill occupations sharply contracted in the 1980s and expanded thereafter (Autor, Katz and Kearney 2008), the reconciliation of these facts is found in Figure 3, which plots the evolution of employment in the set of occupations that comprised the lowest skill quintile of employment in 1980. This figure reveals that low-skill service and low-skill non-service occupations have exhibited strongly countervailing employment trends in every decade after the 1970s. After a contraction of employment in both service and non-service occupations in the 1970s, employment in service occupations rose consistently and with growing velocity in the 1980s, 1990s, and 2000s. Conversely, employment in low-skill non-service occupations continued to fall in each decade. ${ }^{7}$ These divergent trends led to a net decline in low skill employment in the 1980s and a net rise in the 1990s forward. Nevertheless, the growth of service occupations clearly commenced in the 1980s.

These simple exercises make a critical point: to interpret the pronounced polarization of employment and wages in the U.S. and potentially in other advanced countries, it is necessary to understand the rapid rise of employment and wages in service occupations. The primary hypothesis advanced by this paper is that polarization is driven by the interaction between two forces: consumer preferences, which favor variety over specialization; and non-neutral technological progress, which greatly reduces the cost of accomplishing routine, codifiable job tasks but has a comparatively minor impact on the cost of performing in-person service tasks. If consumer preferences do not admit close substitutes for the tangible outputs of service occupations - such as restaurant meals, house-cleaning, security services, and home health assistance - non-neutral technological progress concentrated in goods production (by which we mean non-service occupation activities) has the potential to raise aggregate demand for service outputs and ultimately increase employment and wages in service occupations.

We develop these implications in a general equilibrium model of 'routine-task' replacing technological change, building upon Autor, Levy and Murnane (2003, ALM hereafter), Weiss (2008),

\footnotetext{
${ }^{6}$ The figure uses data from the 1980 Census and 2005 ACS and is calculated using a simple variant of the DiNardo, Fortin and Lemieux (1996) density reweighting method. Further details are given in the figure notes.

${ }^{7}$ Occupational skill percentile is measured by the mean occupational wage in 1980, as in Figure 1. In 1980 , 47 percent of employment in the lowest quintile was in service occupations and 92 percent of service occupation employment was in the lowest quintile. In 2005, 55 percent of employment in the lowest quintile was in service occupations and 89 percent of service occupation employment was in the lowest quintile.
} 
Panel A

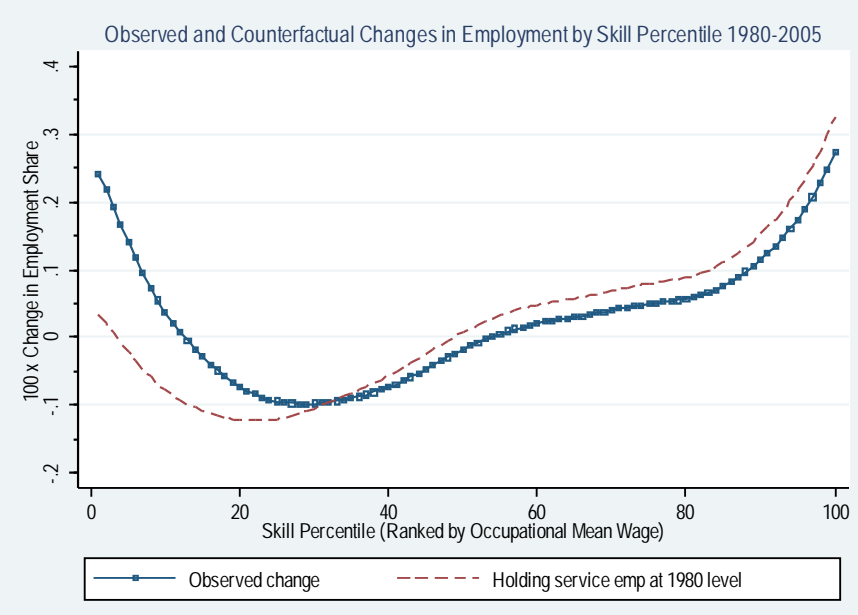

Panel B

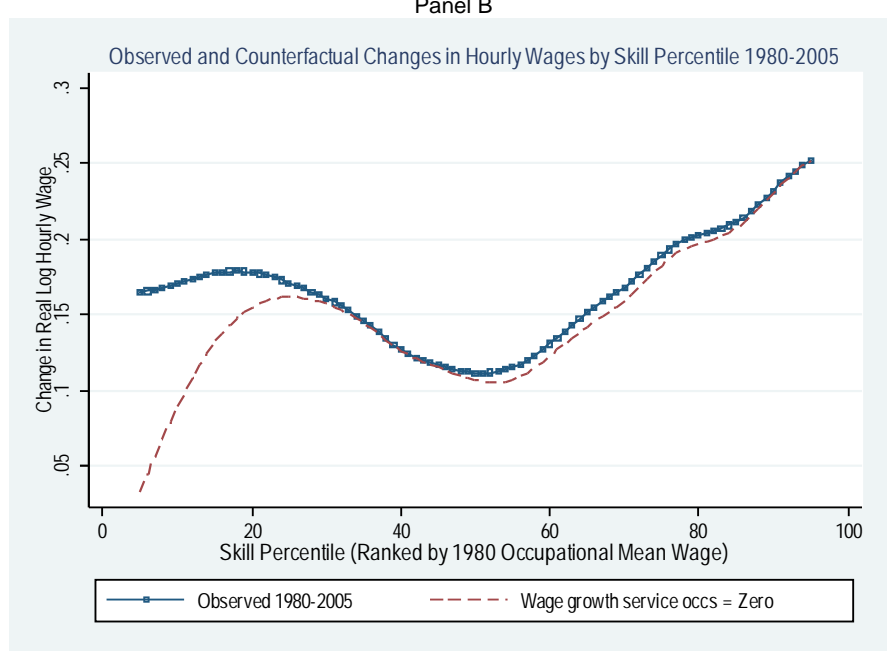

Figure 2.

Smoothed Changes in Employment (Panel A) and Hourly Wages (Panel B) by Skill Percentile, 1980-2005.

Notes: To construct the counterfactual in Panel A, we pool ACS data from 2005 with Census data from 1980 and estimate a weighted logit model for the odds that an observation is drawn from 1980 Census sample (relative to the actual sampling year), using as predictors a service occupation dummy and an intercept. Weights used are the product of Census sampling weights and annual hours of labor supply. We reweight observations in 2005 using the estimated odds multiplied by the hours-weighted Census sampling weight, effectively weighting downward the frequency of service occupations in 2005 to their 1980 level. Given the absence of other covariates in the model, the extra probability mass is implicitly allocated uniformly over the remainder of the distribution. We calculate the counterfactual change in service occupation wages in Panel B by assigning to each service occupation in 2005 its 1980 real log wage level plus the mean log wage change between 1980 and 2005 in production, craft and repair occupations, and operator, fabricator and laborer occupations, all of which have comparably low education levels.

and in a broader sense, Baumol's (1967) model of unbalanced technological progress. ${ }^{8}$ Technological progress in our model takes the form of an ongoing decline in the cost of computerizing routine tasks, which can be performed both by computer capital and low skill ('non-college') workers in the production of goods. The adoption of computers substitutes for low skill workers performing routine

\footnotetext{
${ }^{8}$ In related work, Ngai and Pissarides (2007) derive a multi-sector model where unbalanced productivity growth leads to rising employment in sectors that have low TFP growth. Acemoglu and Guerrieri (2007) develop a model in which endogenous technological change leads to unbalanced technological progress due to differential progress in capital relative to labor-intensive technologies.
} 


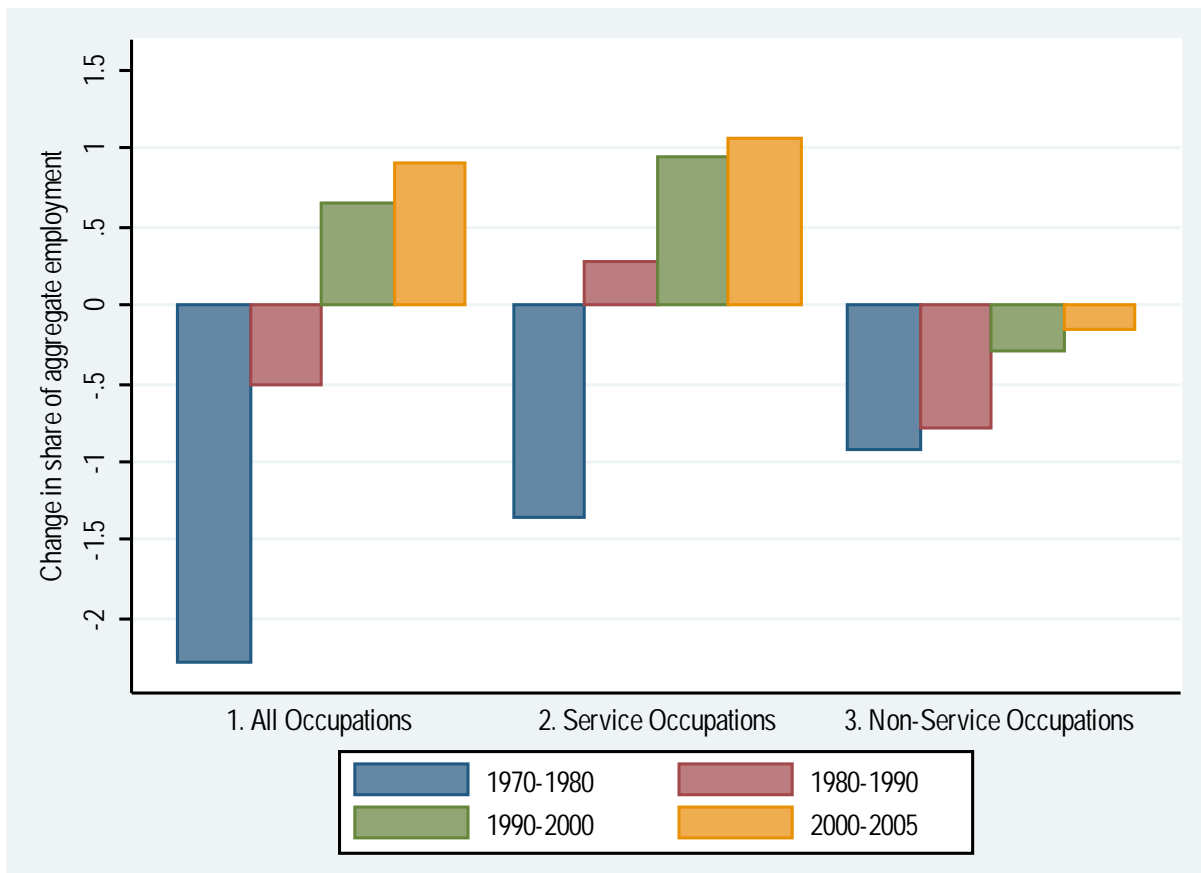

Figure 3.

Change in Aggregate Employment Share by Decade 1970 through 2005 in Occupations Comprising the Lowest Skill Quintile of Employment in 1980

tasks-such as bookkeeping, clerical work, and repetitive production and monitoring activities-which are readily computerized because they follow precise, well-defined procedures. Importantly, occupations intensive in these tasks are most commonplace in the middle of the occupational skill and wage distribution.

The secularly falling price of accomplishing routine tasks using computer capital complements the 'abstract' creative, problem-solving, and coordination tasks performed by highly-educated workers such as professionals and managers, for whom data analysis is an input into production. Critically, automation of routine tasks neither directly substitutes for nor complements the core jobs tasks of low-education occupations - service occupations in particular - that rely heavily on 'manual' tasks such as physical dexterity and flexible interpersonal communication. ${ }^{9}$ Consequently, as computerization erodes the wage paid to routine tasks in the model, low skill workers reallocate their labor supply to service occupations.

A key implication of the model is that when the elasticity of substitution in production between computer capital and routine labor is higher than the elasticity of substitution in consumption between goods and services, then the continuously falling price of computers ultimately causes wages for low skill labor performing routine tasks to fall relative to wages for low skill labor performing

\footnotetext{
${ }^{9}$ The physical and interpersonal activities performed in service occupations - such as personal care, table-waiting, order-taking, housekeeping, janitorial services - have proven cumbersome and expensive to computerize. The reason, explained succinctly by Pinker (2007, p. 174), is that, "Assessing the layout of the world and guiding a body through it are staggeringly complex engineering tasks, as we see by the absence of dishwashers that can empty themselves or vacuum cleaners that can climb stairs."
} 
manual tasks. Low skill labor flows accordingly from goods to services, while high skill labor remains in goods production, leading to employment polarization. Furthermore, wage polarization occurs if the elasticity of substitution between goods and services in consumption does not exceed unity - that is, goods and services are at least weakly complementary. If so, the wages paid to manual tasks (and hence non-college earnings) converge to a steady growth rate that equals or exceeds the growth rate of college wages.

Building on the observation that the output of low-skill service occupations is non-storable and non-tradable-hence, suppliers and demanders of in-person services must collocate-we extend the conceptual model to a spatial equilibrium setting where local labor markets have differential degrees of specialization in routine-intensive industries. This extension provides testable implications for four local labor market outcomes. Specifically, it predicts that markets that were historically specialized in routine task-intensive industries should differentially (i) adopt computer technology and displace workers from routine task-intensive occupations; (ii) undergo employment polarization as low skill labor reallocates into manual task-intensive in-person services; (iii) exhibit larger (nominal) wage growth at both ends of the occupational skill distribution (i.e., wage polarization); and (iv) experience larger net inflows of workers with both very high and very low education, driven by rising demand for both abstract labor in goods production and manual labor in service production.

We test these predictions at the level of 722 consistently defined, fully inclusive Commuting Zones (approximating local labor markets), and find robust support. Using Census data on industry and occupation mix by local labor market and data from the Dictionary of Occupational Titles (U.S. Department of Labor, 1977) on job tasks by occupation, we first document that the specialization of local labor markets in routine activities in the 1980s forward is largely pre-determined by industry structure in 1950 - three decades prior to the era of service occupation growth - which allows us to use the 1950 industry mix as an instrumental variable for local labor market specialization in routine tasks in later decades.

We find that commuting zones that were historically specialized in routine intensive occupations experienced differential increases in workplace computer use and reductions of employment in routine task-intensive jobs after 1980. Simultaneously, they experienced a sharp differential rise in low skill service occupation employment that was accompanied by a differential growth of wages in these occupations. These patterns of growth in service occupations contribute to increased employment and wage polarization in routine-intensive local labor markets.

Alongside unbalanced technological progress, we evaluate numerous alternative explanations for the pronounced differences in wage and employment polarization across more and less routineintensive labor markets, including deindustrialization, offshoring, rising demand for home production substitutes among households with high education and earnings, and growing low-skill immigration. None of these alternatives appears central to our findings.

Our local labor market analysis is most closely related to Beaudry, Doms and Lewis (2010), who explore the cross-city relationship between skilled labor supply, the diffusion of information technology, and the evolution of the skilled wage premium. They document that cities that were 
initially relatively skill-abundant as of 1980 differentially adopted computer technology thereafter, and that this coincided with a reversal of the downward sloping city-level relationship between local skill supply and the skill premium. In addition to corroborating this complementarity between information technology and high skill labor, the main contribution of our paper is to document and analyze the largely unstudied relationship between the diffusion of information technology, the demand for low-skill service activities, and the polarization of employment and wages. ${ }^{10}$

In the next section, we outline a model of unbalanced productivity growth and derive implications for the evolution of occupational composition, skill allocations, and wage inequality. Section 2 describes the data sources and details how we measure local labor markets, job tasks and, in particular, routine task-intensity. Section 3 presents empirical tests of the model's four main predictions for computer adoption, task specialization, wage polarization, and geographic mobility. Section 4 concludes.

\section{Model}

We consider an economy with two sectors $(j=g, s)$ that produce 'goods' and 'services' for consumption using four factors of production. ${ }^{11}$ Three of these factors are labor (task) inputs: manual, routine and abstract $\left(L_{m}, L_{r}, L_{a}\right)$. These labor inputs are supplied by workers of two skill levels $(i=H, U)$ corresponding to high and low skill workers. The fourth factor of production is computer capital $K$, which is an intermediate (non-consumption) good that also provides routine task services. In each sector, a continuum of mass one of firms produces output.

Production of goods combines routine labor, abstract labor, and computer capital, measured in efficiency units, using the following technology:

$$
Y_{g}=L_{a}^{1-\beta}\left[\left(\alpha_{r} L_{r}\right)^{\mu}+\left(\alpha_{k} K\right)^{\mu}\right]^{\beta / \mu},
$$

with $\beta, \mu \in(0,1)$. In this production function, the elasticity of substitution between abstract labor and total routine task input is 1 while the elasticity of substitution between routine labor and computer capital is $\sigma_{r}=1 /(1-\mu)$ and, by assumption, is greater than 1 . By implication, $K$ is a relative complement to abstract labor and a relative substitute for routine labor.

The second sector, which produces services, uses only manual labor, measured in efficiency units as $L_{m}$ :

$$
Y_{s}=\alpha_{s} L_{m}
$$

\footnotetext{
${ }^{10}$ Complementary research by Goos, Manning and Salomons (2010) uses harmonized data from 16 European Union countries to study employment growth across 21 occupation groups from 1993 to 2006. Consistent with our findings, GMS conclude that declining employment in routine-intensive middle-skill occupations is the primary force behind employment polarization. Our paper capitalizes on the longer time horizon and much greater occupational and geographic detail afforded by U.S. data sources to analyze polarization at the level of local labor markets over 45 years. Exploiting local labor market patterns of industry specialization evident in 1960, we tie historical local labor market specialization in routine activities to subsequent growth in employment in service occupations, increasing computer use, changing wage patterns, and labor mobility from 1980 through 2005.

${ }^{11}$ What we specifically have in mind is that the 'service' sector provides low skill in-person services such as haircutting and food service. The 'goods' sector involves all other economic activities, including manufacturing industries and skilled service industries such as banking or higher education.
} 
where $\alpha_{s}>0$ is an efficiency parameter. We will normalize $\alpha_{s}$ to 1 in the rest of the paper, and so $\alpha_{r}$ may be thought of as a relative efficiency term.

There is a continuum of mass one of high skill workers, $H$, who supply abstract labor inelastically to the goods sector. There is a continuum of mass one of low skill workers, $U$, each of whom supplies either manual or routine labor.

Low-skill workers have homogeneous skill at performing manual tasks. If all $U$ workers were to perform manual tasks, they would supply a unit mass of manual labor. Low skill workers have heterogeneous skills in performing routine tasks. Let $\eta$ equal a worker's skill in routine tasks, measured in efficiency units, with density and distribution functions $f(\eta)$ and $F(\eta)$. There is a mass of one of potential routine labor input: $\int \eta f(\eta) d \eta=1$. Each worker of type $U$ supplies labor inelastically to the task offering the highest income level given her endowment, $\eta$. Hence, a low skill worker supplies routine tasks only if his earnings in goods production exceeds the (uniform) service wage (i.e., $w_{r}(t) \times \eta_{i} \geq w_{m}(t)$ ). To permit analytic solutions of the model, it is convenient to choose a functional form for $f(\eta)$. We assume that $\eta$ is distributed exponentially on the interval $[0, \infty]$ with $f(\eta)=e^{-\eta} .{ }^{12}$ Given the positive self-selection and attendant higher earnings of low skill workers in goods relative to service occupations, workers in service occupations tend to be at the bottom of the wage-ranked occupational skill distribution (i.e., at the left-hand side of polarization graphs) while routine occupations are towards the middle of the distribution.

Computer capital is produced and competitively supplied using the following technology:

$$
K=Y_{k}(t) e^{\delta t} / \theta
$$

where $Y_{k}(t)$ is the amount of the final consumption good allocated to production of $K, \delta>0$ is a positive constant, and $\theta=e^{\delta}$ is an efficiency parameter. Capital fully depreciates between periods. ${ }^{13}$ Productivity is rising at $\delta$, reflecting technological progress.

At time $t=1$, one unit of the consumption good $Y$ can be used to produce one efficiency unit of computer capital: $1=e^{\delta} / \theta$. Competition guarantees that the real price of computer capital (per efficiency unit) is equal to marginal (and average) cost. So, at time $t=1, p_{k}=1$. As time advances, this price falls, with

$$
p_{k}(t)=\frac{Y_{k}}{K}=\theta e^{-\delta t}
$$

To close the model, we model all consumers/workers as having identical CES utility functions defined over consumption of goods and services:

$$
u=\left(c_{s}^{\rho}+c_{g}^{\rho}\right)^{1 / \rho}, \text { where } \rho<1 .
$$

The elasticity of substitution in consumption between goods and services is $\sigma_{c}=1 /(1-\rho)$.

Consumers take prices and wages as given and maximize utility subject to the budget constraint that consumption equals wages. Firms maximize profits taking the price of consumption goods and wages as given. The CRS technology ensures that equilibrium profits will be zero.

\footnotetext{
${ }^{12}$ The choice of functional form is innocuous given that the long run equilibrium of the model (i.e., as $t \rightarrow \infty$ ) depends only on technology, preferences, and factor endowments (i.e., $H$ and $U$ ).

${ }^{13}$ More precisely, the flow of services provided by computer capital is paid its rental price continually as these services are consumed.
} 
We are interested in the long-run $(t \rightarrow \infty)$ allocation of low-skilled labor to goods and services and the evolution of inequality, measured by the manual to abstract and manual to routine wage ratios. We present the static solution of the model and its asymptotic equilibrium immediately below and subsequently extend the model to a spatial equilibrium setting.

\subsection{The planner's problem}

Since there are no distortions, the equilibrium allocation can be characterized by solving the social planner's problem. In each time period, the planner chooses the level of capital $K(t)$, and the allocation of labor $L_{m}(t)$ to manual tasks in the service sector that maximize aggregate utility. ${ }^{14}$

Given $p_{k}(t)$ at time $t$, the social planner's problem at time $t$ can be written as:

$$
\begin{aligned}
& \max _{K, L_{m}}\left(L_{m}^{\frac{\sigma-1}{\sigma}}+\left(Y_{g}-p_{k}(t) K\right)^{\frac{\sigma-1}{\sigma}}\right)^{\frac{\sigma}{\sigma-1}} \\
\text { where } Y_{g}= & L_{a}^{1-\beta} X^{\beta} \text { and } X \equiv\left[\left(\alpha_{r} L_{r}\right)^{\mu}+\left(\alpha_{k} K\right)^{\mu}\right]^{1 / \mu}, \\
& L_{r}=g\left(L_{m}\right) \equiv\left(1-\log \left(1-L_{m}\right)\right)\left(1-L_{m}\right),
\end{aligned}
$$

where $X$ is the aggregate input of routine tasks, $g(\cdot)$ is a function with the property that $g(0)=1$ and $g(1)=0$, and we use $\sigma$ in place of $\sigma_{c}$ to simplify notation.

The first order conditions for problem (6) with respect to capital $K$ and labor $L_{m}$ respectively are given by:

$$
\begin{aligned}
\frac{\partial Y_{g}}{\partial K} & =p_{k}(t) \\
L_{m}^{-1 / \sigma} & =\left(Y_{g}-p_{k} K\right)^{-1 / \sigma} \frac{\partial Y_{g}}{\partial X} \frac{\partial X}{\partial L_{r}}\left(-\log \left(1-L_{m}\right)\right),
\end{aligned}
$$

where we have used $g^{\prime}\left(L_{m}\right)=\log \left(1-L_{m}\right)=-\eta^{*}$.

The system in (7) and (8) contains two unknowns $\left(L_{m}, X\right)$ in two equations and uniquely solves for the equilibrium at any time $t$. We use these equations to first solve for the asymptotic allocation of low skill labor between goods and services and then to solve for equilibrium wages.

\subsection{Asymptotic labor allocation}

Since the price of computer capital $p_{k}(t)$ falls to zero asymptotically, computer capital limits to

$$
\lim _{t \rightarrow \infty} K(t)=\infty .
$$

Noting that $L_{r}$ is bounded from above and $L_{r}$ and $K$ are gross substitutes in the production of $X$, the production of $X$ in the limit will be essentially determined by the capital level. Formally:

$$
\lim _{t \rightarrow \infty} X / \alpha_{k} K=1
$$

\footnotetext{
${ }^{14}$ The equilibrium at each time can be analyzed in isolation because capital fully depreciates between periods and consumption equals output. The price of computer capital falls exogenously over time, and the equilibrium prices of all factors follow from their marginal products.
} 
Using this equation and Eq. (9), the supplementary Theory Appendix shows that the asymptotic supply of low skill labor to services, $L_{m}^{*}$, is uniquely determined as follows: ${ }^{15}$

$$
L_{m}^{*}=\left\{\begin{array}{cl}
1 & \text { if } \frac{1}{\sigma}>\frac{\beta-\mu}{\beta} \\
\bar{L}_{m} \in(0,1) & \text { if } \frac{1}{\sigma}=\frac{\beta-\mu}{\beta} \\
0 & \text { if } \frac{1}{\sigma}<\frac{\beta-\mu}{\beta}
\end{array} .\right.
$$

This equation indicates that the allocation of low skill labor between services (manual tasks) and goods (routine tasks) depends upon the relative magnitudes of the consumption and production elasticities $\left(\sigma\right.$ and $\sigma_{r}=1 /(1-\mu)$, respectively), scaled by the share of the routine aggregate in goods production $(\beta)$.

To see the intuition for this limiting result, consider a case where $\beta=1$, so that equation (11) simplifies to $\frac{\sigma_{r}}{\sigma} \gtreqless 1$. In this case, the asymptotic allocation of low skill labor to services versus goods production depends entirely on whether the elasticity of substitution in production between computer capital and routine labor is higher or lower than the elasticity of substitution in consumption between goods and services (both of which demand low skill labor). If the production elasticity exceeds the consumption elasticity, technological progress (i.e., a falling computer price $p_{k}$ ) raises relative demand for low skill labor in service employment; in the limit, all low skill labor flows from goods into services production. If this inequality is reversed, all low skill labor eventually concentrates in the goods sector, where it performs routine tasks (opposite to what is observed in the data). ${ }^{16}$

\subsection{Asymptotic wage inequality}

Two measures of inequality are relevant for our analysis. The first is the relative wage paid to manual versus routine tasks. When this ratio falls, wages in routine production occupations (in the middle of the occupational wage distribution) grow relative to wages in service occupations at the bottom of the distribution. The second is the relative wage paid to abstract versus manual tasks, reflecting earnings inequality between occupations at the top and bottom of the occupational skill distribution. In our terminology, a monotone increase in inequality is a case where $w_{a} / w_{m}$ rises and $w_{m} / w_{r}$ falls. In contrast, wage polarization occurs when $w_{m} / w_{r}$ rises while $w_{a} / w_{m}$ is either stable or declining. We now derive the necessary and sufficient conditions for these outcomes.

Since low skill labor necessarily flows towards the sector/task that offers the highest wage, the dynamics of $w_{m} / w_{r}$ precisely mirror the dynamics of labor flows between goods and services (11).

\footnotetext{
${ }^{15}$ Here, $\bar{L}_{m}$ is the solution to the equation $\left(\bar{L}_{m}\right)^{-1 / \sigma}=\kappa_{1}^{-1 / \sigma} \kappa_{2} g\left(\bar{L}_{m}\right)^{\mu-1}\left(-\log \left(1-\bar{L}_{m}\right)\right)$. See the Appendix for details.

${ }^{16}$ The role played by $\beta$ in this equation is also straightforward. If $\beta$ is low, a relatively small share of the gains to technical progress accrue to low skill labor performing routine tasks (through q-complementarity) and a correspondingly larger share accrues to high skill labor performing abstract tasks. Hence, the lower is $\beta$, the smaller is the critical value of $\sigma_{r} / \sigma$ required for low skill labor to flow into services.
} 
Specifically:

$$
\frac{w_{m}}{w_{r}}=\left\{\begin{array}{c}
\infty \text { if } \frac{1}{\sigma}>\frac{\beta-\mu}{\beta} \\
-\log \left(1-L_{m}^{*}\right) \text { if } \frac{1}{\sigma}=\frac{\beta-\mu}{\beta} . \\
0 \text { if } \frac{1}{\sigma}<\frac{\beta-\mu}{\beta} .
\end{array}\right.
$$

If the production elasticity exceeds the consumption elasticity (scaled by $\beta$ ), wages for low skill workers in manual tasks rise relative to the alternative wage in routine tasks, and low skill labor flows to service occupations at the bottom of the occupational skill distribution. Therefore, the lower tails of both the wage and employment distributions 'polarize.'

This polarization is necessary but not sufficient for overall wage polarization to occur. The additional condition needed is that wages in service occupations grow at least as rapidly as high skill wages (i.e., is $w_{a} / w_{m}$ is either constant or declining). ${ }^{17}$ The supplementary Theory Appendix shows that this occurs if the consumption elasticity is not less than unity - that is, goods and services are gross complements: ${ }^{18}$

$$
\frac{w_{a}}{w_{m}}=\left\{\begin{array}{l}
0 \text { if } \sigma<1 \\
1 \text { if } \sigma=1 \\
\infty \text { if } \sigma>1
\end{array}, \text { when } \frac{1}{\sigma}>\frac{\beta-\mu}{\beta} .\right.
$$

This result is of signal importance to our analysis because it underscores that despite ongoing, skilled labor augmenting technological progress and a fixed skill endowment, wage inequality need not rise indefinitely. If goods and services are at least weakly complementary, inequality between high and low skill labor either asymptotes to a constant or reverses course. Thus, consumer preferences determine whether the rising marginal physical product of high skill workers translates into a corresponding rise in their marginal value product.

\subsection{Summary of closed economy model}

The closed economy model gives rise to three focal cases. First, if the elasticity of substitution in production between computer capital and routine labor is high relative to the elasticity of substitution in consumption between goods and services (specifically, $1 / \sigma>(\beta-\mu) / \beta$ ), the continuously falling price of automating routine tasks ultimately causes wages in manual tasks to exceed wages in routine tasks. Low skill labor flows accordingly from goods to services - though not instantaneously since some low skill workers have strong initial comparative advantage in routine tasks. Because routine task-intensive occupations, such as clerical and repetitive production jobs, are typically found towards the middle of the occupational skill distribution, we say that employment 'polarizes.' Note, however, that because workers who remain in the goods sector are positively selected, the ratio of wages paid to workers in goods versus service occupations need not fall as rapidly as the ratio of wages paid to an efficiency unit of routine versus manual task input. The observed change in wages per time unit may thus be smaller than the underlying change in wages per efficiency unit.

\footnotetext{
${ }^{17}$ If by contrast, $w_{a} / w_{m}$ were to continue to rise, wages in manual tasks would eventually become arbitrarily small relative to wages in abstract tasks (even while $w_{m}$ is rising in absolute terms). This would not accord with our definition of wage polarization.

${ }^{18}$ The Theory Appendix also characterizes the behavior of $\frac{w_{a}}{w_{m}}$ when $\frac{1}{\sigma}<\frac{\beta-\mu}{\beta}$, which can only occur when goods and services are gross substitutes $(\sigma>1)$.
} 
Second, if in addition, the consumption elasticity is less than or equal to unity $(1 / \sigma \geq 1>$ $(\beta-\mu) / \beta)$, employment polarization is accompanied by wage polarization whereby the ratio of wages paid to manual relative to abstract tasks is either constant or increasing.

Third, if instead the production elasticity is low relative to the consumption elasticity $(1 / \sigma<$ $(\beta-\mu) / \beta)$, ongoing technological progress competes down the wage paid in routine relative to abstract tasks but does not raise demand for services sufficiently to increase the manual relative to routine wage; wages and employment fall most at the bottom of the occupational skill distribution. This case corresponds most closely to the monotone skill-biased technological setting considered by the canonical model. It does not, however, appear to be the case best supported by the data.

\subsection{Spatial equilibrium}

To guide the subsequent empirical analysis of polarization at the level of local labor markets, we extend the closed economy model to consider an integrated, spatial equilibrium setting. In this setting, mobile high skill workers reallocate across regions in response to changes in real earnings induced by the interaction between a uniformly falling price of automating routine tasks and regional heterogeneity in industry specialization that affect regions' ability to capitalize on these technological advances.

We consider a large set of geographic regions, $j \in J=\{1, . .,|J|\}$, each endowed with a unit mass of high skill labor and a unit mass of low skill labor, with labor supply as above. To introduce regional specialization, we adopt the Armington (1969) assumption that products are differentiated by origin. ${ }^{19}$ In each region, a continuum of competitive firms produces differentiated consumption goods $Y_{g, j}$ using the technology

$$
Y_{g, j}=L_{a, j}^{1-\beta_{j}}\left[\left(\alpha_{r} L_{r, j}\right)^{\mu}+\left(\alpha_{k} K_{j}\right)^{\mu}\right]^{\beta_{j} / \mu},
$$

with $\beta_{j} \in(0,1)$. A higher value of $\beta_{j}$ implies that the differentiated good produced in that region is relatively more intensive in the routine task aggregate, while a lower level of $\beta_{j}$ corresponds to relatively high demand for abstract tasks in goods production. To simplify the analysis, we assume also that $\beta_{j}$ is different for each region. In particular, there exists a region $j^{\text {max }}$ such that $\beta_{j^{\max }}=\max _{j} \beta_{j}$, and a region $j^{\min }$ such that $\beta_{j_{\min }}=\min _{j} \beta_{j}$. Competitive firms in each region use low skill labor to produce service output as per Eq. (2).

Goods are costlessly tradable across regions. Services are non-tradable since they must be performed in person. Consistent with the observation that geographic mobility is higher among college than non-college workers (Topel, 1986, Bound and Holzer, 2000, and Notowidigdo, 2010), we posit that high skill labor is fully mobile across regions while low skill labor is not. We discuss below how relaxing this assumption would affect the results.

\footnotetext{
${ }^{19}$ A large body of work documents persistent regional patterns of industry specialization that arise from locationspecific productive attributes - such as climate or access to ports - or from agglomeration economies (e.g., Krugman, 1991, Blanchard and Katz, 1992, Ellison and Glaeser, 1997, and Glaeser and Gottlieb, 2009). We take these regional differences as given here. The subsequent empirical analysis uses historical measures of local area industry mix in 1950 to capture longstanding geographic differences in regional specialization.
} 
We assume that each region admits a representative household with preferences given by:

$$
u\left(c_{s}, c_{g 1}, \ldots, c_{g J}\right)=u\left(c_{s}^{\rho}+\tilde{c}^{\rho}\right)^{1 / \rho},
$$

where

$$
\tilde{c}=\left(\sum_{j=1}^{J} c_{j}^{\nu}\right)^{1 / \nu}
$$

with $\nu>0$, implying that the goods from each region are gross substitutes. These preferences differ from our initial setup (Eq. 5) only in that we allow for consumer substitution between locally produced services and the full set of consumption good varieties.

We make two further simplifications for expositional ease. First, we consider only the focal case in which the consumption elasticity $\sigma$ is equal to unity. This simplification is not restrictive since, as per equation (13), the aggregate model gives rise to employment and wage polarization for any substitution elasticity less than or equal to unity. Second, because our empirical work explores variation in employment, wages, and mobility across local labor markets but does not analyze trade in goods, we make the simplifying assumption that all regional goods varieties are perfect substitutes in consumption (i.e., $\nu \rightarrow-\infty$ in equation 15). Perfect substitutability ensures that goods prices are equated across regional economies. ${ }^{20}$

The Online Theory Appendix provides a detailed solution of the spatial equilibrium model, which closely resembles the closed economy model above. Its key feature is that a uniform decline in the computer price across all regions - caused by continuous technological progress in computer production - has differential effects on local labor markets whose production is intensive in routine tasks (i.e., where $\beta_{j}$ is greater). The main predictions of the model are summarized next.

\subsection{Empirical implications}

The spatial equilibrium results provide four main empirical implications that we test in section 3 . As the price of computer capital falls, the model predicts that local labor markets with greater initial specialization in routine tasks (a higher 'routine share') will experience:

1. Greater adoption of information technology, coinciding with the displacement of labor from routine tasks;

2. Greater reallocation of low skill workers from routine task-intensive occupations to service occupations;

3. Larger increases in wages for both high skill abstract and low skill manual labor (i.e., wage polarization), driven by the q-complementarity between information technology and abstract tasks in production and the gross complementarity between goods and services in consumption. The model makes clear that these regional wage differentials are nominal, however, since real wage differentials across regions are arbitraged by high skill mobility; ${ }^{21}$

\footnotetext{
${ }^{20}$ In equilibrium, however, goods trade does not occur since with only one tradable commodity and perfect substitutability among varieties, there are no gains from trade.

${ }^{21}$ Although the declining price of computer capital raises real earnings in aggregate, high skill labor mobility
} 
4. Larger net inflows of high skill labor, driven by the interaction between differential adoption of computer capital in initially routine task-intensive labor markets and q-complementarity between computer capital and high skill labor.

Two elements omitted from the model deserve note. A first is our stylized assumption that high but not low skill labor is mobile across regions. Allowing for low skill labor mobility in our setup would lead to qualitatively similar results in that both high and low skill workers would differentially migrate towards the region with the highest routine share given its greater rate of capital accumulation and higher labor productivity growth - a conjecture that we confirm below. ${ }^{22}$

A second element of realism intentionally omitted from the model is the potential for aggregate skill supplies to respond to changes in the skilled wage differential. Allowing for endogenous skill investments would clearly temper the extremes of wage inequality that can arise in the model. ${ }^{23}$ We omit this consideration to emphasize that even with skill supplies held constant, ongoing skilled labor augmenting technical change need not imply ever rising wage inequality.

\section{Data sources and measurement}

We summarize our data construction and measurement in this section, with many further details on sample construction, geographic matching and occupational classification scheme found in the supplementary Data Appendix.

\subsection{Data sources}

Large sample sizes are essential for an analysis of changes in labor market composition at the detailed geographic level. Our analysis draws on the Census Integrated Public Use Micro Samples (Ruggles et al. 2004) for the years 1950, 1970, 1980, 1990, and 2000 and the American Community Survey (ACS) for 2005. ${ }^{24}$ The Census samples for 1980, 1990 and 2000 include 5 percent of the U.S. population, the 1970 Census and ACS sample include 1 percent of the population, and the 1950 Census sample includes approximately 0.2 percent of the population.

Our worker sample consists of individuals who were between age 16 and 64 and who were working in the year preceding the survey. Residents of institutional group quarters such as prisons and

eliminates any real geographic wage differentials, so higher nominal wages in a region are fully offset by a higher cost of living. Moretti (2008) presents evidence that the prices of housing, goods and services are all higher in high-wage, high-education cities, and that these price differentials may offset a some fraction of the higher nominal wages of high skill workers in these locations.

${ }^{22}$ More formally, our setup does not accommodate simultaneous high and low skill migration without further assumptions because, without a locally fixed factor that becomes scarcer as workers flow into high routine share regions, full mobility readily gives rise to a case where all labor relocates to the region with the highest $\beta_{j}$. This feature of the model can be amended, at some cost in complexity, by making the plausible assumption that each regional variety $Y_{g j}$ faces a downward sloping aggregate demand curve (as in Eq. 15).

${ }^{23}$ Indeed, in our data, the college share of worked hours rises from 42 to 62 percent between 1980 and 2005.

${ }^{24}$ The 1960 Census lacks detailed geographic information. The 1950 sample-line subsample on which we rely is only one-fifth as large as the full 1 percent public use sample, but it contains education and occupation variables, which are key to our analysis. 
psychiatric institutions are dropped along with unpaid family workers. Labor supply is measured by the product of weeks worked times usual number of hours per week. All calculations are weighted by the Census sampling weight multiplied with the labor supply weight and a weight derived from the geographic matching process that is described below.

Our analysis requires a time-consistent definition of local labor markets. Previous research has often used Metropolitan Statistical Areas (MSAs) as a proxy for local labor markets. MSAs are defined by the U.S. Office for Management and Budget for statistical purposes; they consist of a large population nucleus and adjacent communities that have a high degree of social and economic integration with the core city. Two disadvantages of MSAs are that they do not cover rural parts of the U.S. and their geographic definition is periodically adjusted to reflect the growth of cities. This inconsistency is problematic for our analysis because the characteristics of suburban areas that are appended to MSAs are likely to systematically differ from the core cities.

We pursue an alternative definition of local labor markets based on the concept of Commuting Zones (CZs) developed by Tolbert and Sizer (1996), who used county-level commuting data from the 1990 Census data to create 741 clusters of counties that are characterized by strong commuting ties within CZs and weak commuting ties across CZs. Our analysis includes the $722 \mathrm{CZs}$ that cover the mainland of the US (both metropolitan and rural areas). Commuting zones are particularly suitable for our analysis of local labor markets because they cover the entire U.S., are based primarily on economic geography rather than incidental factors such as minimum population, and can be consistently constructed using Census Public Use Micro Areas (PUMAs) for the full period of our analysis. ${ }^{25}$ We are not aware of prior economic research that makes use of this geographic construct.

\subsection{Measuring the 'routine employment share'}

A crucial input into our analysis is a summary index of routine task activities within commuting zones. We measure routine task activities using the occupational composition of employment. Following ALM (2003), we merge job task requirements from the fourth edition of the US Department of Labor's Dictionary of Occupational Titles (US Department of Labor, 1977; 'DOT' hereafter) to their corresponding Census occupation classifications to measure routine, abstract and manual task content by occupation. ${ }^{26}$ While our theoretical model posits that workers supply either routine, abstract or manual tasks, the DOT permits an occupation to comprise multiple tasks at different levels of intensity. We combine these measures to create a summary measure of routine task-intensity

\footnotetext{
${ }^{25}$ If a PUMA overlaps with several counties, our procedure is to match PUMAs to counties assuming that all residents of a PUMA have equal probability of living in a given county. The aggregation of counties to CZs then allows computing probabilities that a resident of a given PUMA falls into a specific CZ. Further details on our construction of CZs are given in the supplementary appendix and in Dorn (2009). Tolbert and Killian (1987) earlier developed commuting zones using the 1980 Census. These commuting zones are largely but not fully identical to the 1990 definitions.

${ }^{26}$ Following Autor, Katz and Kearney (2006), we collapse ALM's original five task measures to three task aggregates for abstract, routine and manual tasks. Details of our consistent occupation scheme, which provides a balanced panel of occupations covering the 1980, 1990, and 2000 Census and the 2005 ACS, are given in the supplementary appendix and in Dorn (2009).
} 
$R T I$ by occupation, calculated as:

$$
R T I_{k}=\ln \left(T_{k, 1980}^{R}\right)-\ln \left(T_{k, 1980}^{M}\right)-\ln \left(T_{k, 1980}^{A}\right),
$$

where $T_{k}^{R}, T_{k}^{M}$ and $T_{k}^{M}$ are, respectively, the routine, manual and abstract task inputs in each occupation $k$ in $1980 .{ }^{27}$ This measure is rising in the importance of routine tasks in each occupation and declining in the importance of manual and abstract tasks.

Table 2. Task Intensity of Major Occupation Groups

\begin{tabular}{|c|c|c|c|c|}
\hline & $\begin{array}{c}\text { RTI } \\
\text { Index }\end{array}$ & $\begin{array}{c}\text { Abstract } \\
\text { Tasks }\end{array}$ & $\begin{array}{c}\text { Routine } \\
\text { Tasks }\end{array}$ & $\begin{array}{c}\text { Manual } \\
\text { Tasks }\end{array}$ \\
\hline Managers/Prof/Tech/Finance/Public Safety & - & + & - & - \\
\hline Production/Craft & + & + & + & - \\
\hline Transport/Construct/Mech/Mining/Farm & - & - & + & + \\
\hline Machine Operators/Assemblers & + & - & + & + \\
\hline Clerical/Retail Sales & + & - & + & - \\
\hline Service Occupations & - & - & - & + \\
\hline
\end{tabular}

To illuminate the operation of the routine task-intensity measure, Table 2 provides a schematic summary of the RTI variable and its constituent components. Evident from the table is that the intensity of both abstract and manual task activities is roughly monotone (albeit with countervailing signs) in occupational skill while the intensity of routine task activities is highest in the middle of the skill distribution. Thus, the composite RTI index takes low values at the bottom of the occupational skill distribution, where manual tasks dominate, and at the top of the occupational skill distribution, where abstract tasks dominate. Service occupations stand out as the only major occupation group that combines high manual task content with low routine task content. Appendix Table 1, which enumerates the most and least routine task-intensive non-farm occupations, contains many illustrative examples. ${ }^{28}$

To measure routine task intensity at the geographic level, we take two additional steps. We first use the RTI index to identify the set of occupations that are in the top employment-weighted third of routine task-intensity in 1980. We refer to these as routine-intensive occupations. As shown in Figure 4, routine intensity is inversely U-shaped in occupational skill. The fraction of occupations flagged as routine-intensive is lowest at the $1^{\text {st }}$ and $80^{\text {th }}$ percentiles of the skill distribution and rises smoothly from both locations to a maximum at approximately the $30^{\text {th }}$ skill percentile. ${ }^{29} \mathrm{~A}$

\footnotetext{
${ }^{27}$ Tasks are measured on a zero to ten scale. For the five percent of microdata observations with the lowest manual task score, we use the manual score of the 5th percentile. A corresponding adjustment is made for abstract scores.

${ }^{28}$ The most routine-intensive group includes clerical occupations, accounting occupations, and repetitive-motion occupations. The least routine-intensive, low-education group includes service occupations, transportation and material moving occupations, and blue collar trades. Logically, the least routine-intensive, high-education group includes technical and scientific professions, teaching occupations, and public safety occupations.

${ }^{29}$ There is also a small uptick in the routine occupation share from the $80^{t h}$ through $95^{\text {th }}$ percentiles, which in part reflects the limitations of the DOT task measures. The routine task measure is somewhat higher in technical and scientific occupations than in other high-education occupations, reflecting (in our view) a blurring of the distinction between quantitative reasoning tasks and rote procedural tasks.
} 
visual comparison of Figure 4 and the upper panel of Figure 1 (employment polarization) reveals, consistent with our task framework, that there is a tight correspondence between occupations' routine intensity and their growth rates: employment contracted between 1980 and 2005 at the occupational skill percentiles with highest share of routine occupations.

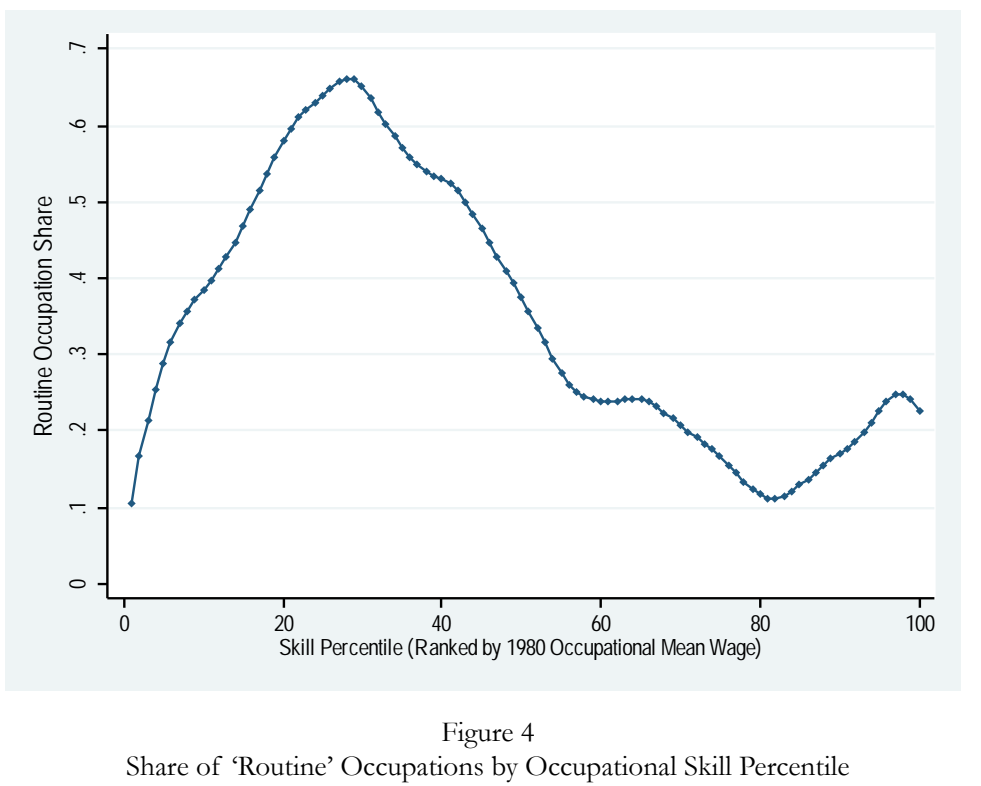

Similarly, a comparison between Figure 4 and the lower panel of Figure 1 (wage polarization) suggests that there is also a negative relationship between occupational routine intensity and wage growth, but the correspondence is not as close as it is for employment. As we discuss further in section 3.3, this discrepancy arises primarily from wage trends in clerical occupations, which are concentrated in the second, third and fourth decile of the occupational skill distribution. These routine-intensive occupations experienced large declines in employment shares, as predicted by the model, but also rising relative wages from 1980 to 2005. A possible explanation for this pattern is that as traditional clerical tasks have succumbed to automation, the work content of the remaining clerical and administrative jobs has become concentrated in more skill-demanding, less routineintensive tasks. For example, the 1976 edition of the Department of Labor's Occupation Outlook Handbook described the job of secretary as: "Secretaries relieve their employers of routine duties so they can work on more important matters. Although most secretaries type, take shorthand, and deal with callers, the time spent on these duties varies in different types of organizations" (U.S. Department of Labor 1976, p. 94). In 2000, the entry for secretary reads: "As technology continues to expand in offices across the Nation, the role of the secretary has greatly evolved. Office automation and organizational restructuring have led secretaries to assume a wide range of new responsibilities once reserved for managerial and professional staff. Many secretaries now provide training and orientation to new staff, conduct research on the Internet, and learn to operate new office technologies" (U.S. Department of Labor 2000, p. 324). This example cautions that the tasks performed within occupations are not necessarily static, and in particular, that occupations 
undergoing rapid computerization may differentially reduce labor input of routine tasks and increase labor input of abstract tasks. ${ }^{30}$

We next calculate for each commuting zone $j$ a routine employment share measure, $R S H_{j t}$, equal to:

$$
R S H_{j t}=\left(\sum_{k=1}^{K} L_{j k t} \cdot 1\left[R T I_{k}>R T I^{P 66}\right]\right)\left(\sum_{k=1}^{K} L_{j k t}\right)^{-1}
$$

where $L_{j k t}$ is the employment in occupation $k$ in commuting zone $j$ at time $t$, and $1[\cdot]$ is the indicator function, which takes the value of one if the occupation is routine-intensive by our definition. By construction, the mean of this measure is 0.33 in 1980, and the population weighted $80 / 20$ percentile range is 7 percentage points $\left(R S H^{P 20}=0.294\right.$ and $\left.R S H^{P 80}=0.365\right)$.

While its simplicity is attractive, there are many plausible ways to construct this measure, and it would be potentially problematic if our core results hinged on one particular choice. To address this concern, we have explored numerous variations of our basic measure of the concentration of routine activities in a commuting zone and have found substantially similar results across specifications. ${ }^{31}$ Online Appendix Table 1 details these results.

\section{Main results}

We now test the model's four main empirical implications concerning computer adoption and displacement of routine tasks; reallocation of non-college labor into service occupations; wage and employment polarization; and geographic mobility.

Prior to the regression analysis, we present summary evidence on one overarching prediction of the analytic framework: commuting zones specialized in routine task-intensive jobs should experience differential employment shifts out of routine occupations in the middle of the occupational skill distribution and into low skill service occupations as information technology substitutes for workers engaged in routine tasks. Figure 5 provides graphical evidence on this prediction. Following the approach of Figure 1 in the Introduction, Figure 5a plots the change between 1980 and 2005 in the employment share at each skill percentile in two sets of commuting zones: those with a routine share above the grand mean in 1980 and those with a routine share below it. ${ }^{32}$ Routine-intensive commut-

\footnotetext{
${ }^{30}$ This concern applies with greatest force to clerical occupations which often comprise a diverse set of tasks. Bartel, Ichniowski and Shaw (2007) also present evidence that some precision production occupations have become less routine-intensive and more abstract-intensive as automation has advanced.

${ }^{31}$ Some of these variations include: replacing the three-factor $R T I$ with a two factor alternative, $R T I=\ln (R)-$ $\ln (M)$; redefining the baseline RTI by measuring the routine task score of an occupation using either the DOT variable "Set Limits, Tolerances, or Standards" or the DOT variable "Finger Dexterity," instead of taking the average of the two; measuring the routine share in each $\mathrm{CZ}$ as the employment share in the top non-college employment-weighted third of routine-intensive occupations; measuring the routine share using the top 25 or 40 percent of occupations rather than the top 33 percent; and using the mean $R T I$ in a commuting zone as a measure of routine-intensity rather than the routine occupation share. These many variants perform quite comparably-in terms of both their effect sizes and statistical significance-in predicting the growth of non-college service employment within commuting zones between 1980 and 2005.

${ }^{32}$ To facilitate comparison with Figure 1, the run variable in the figure corresponds to the overall skill distribution in 1980. Following the suggestion of an anonymous referee, we have also grouped commuting zones into terciles of initial routine share to compare employment and wage polarization between the highest and lowest terciles. Consistent with expectations, the pattern of polarization is more pronounced in this alternative split. Figures are available from the authors.
} 

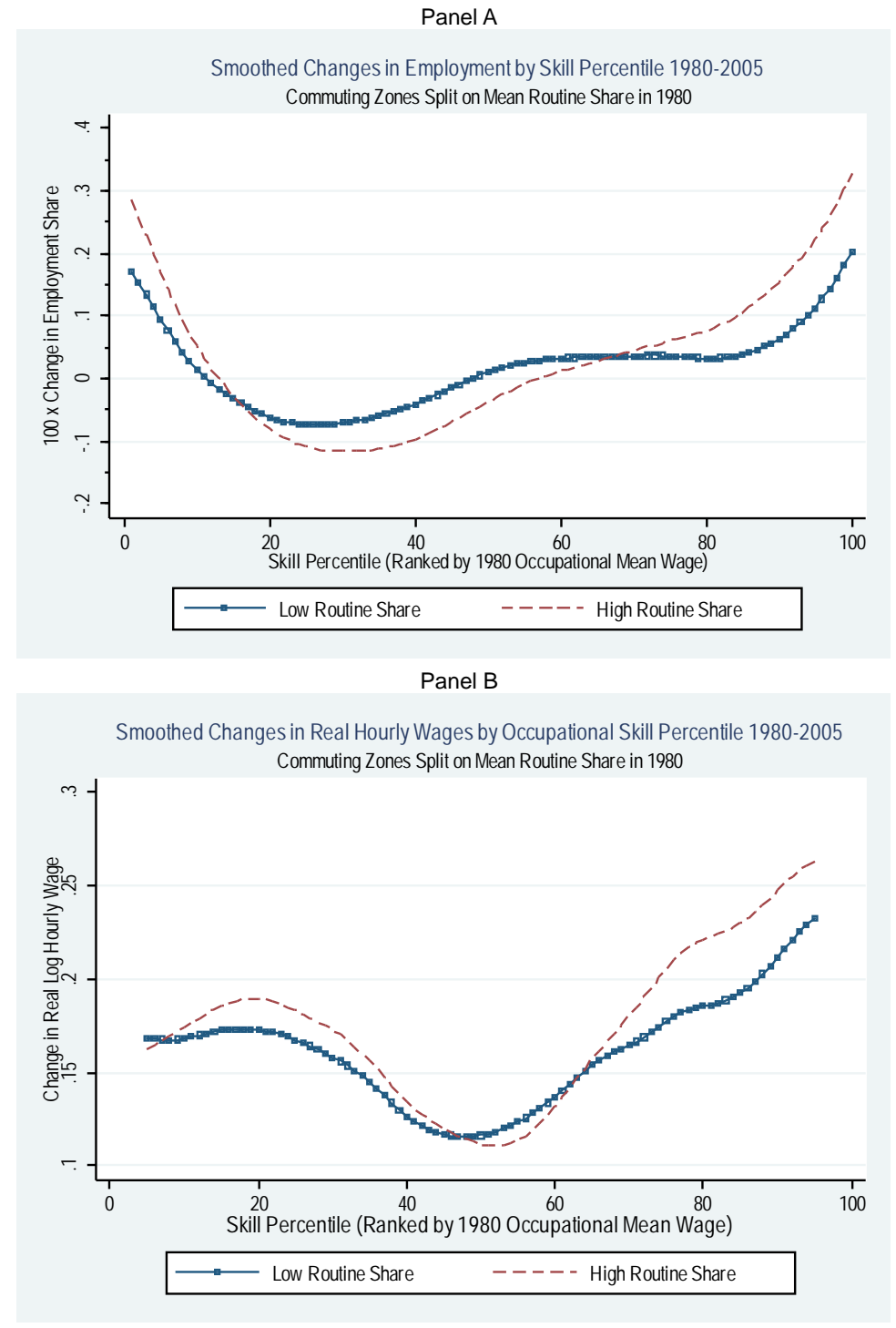

Figure 5.

Smoothed Changes in Employment (Panel A) and Hourly Wages (Panel B) by Skill Percentile in Commuting Zones with High and Low Routine Employment Shares in 1980.

ing zones exhibit a pronounced polarization of employment between 1980 and 2005. Polarization is clearly more subdued in the set of commuting zones with an initially low routine share. We perform the parallel exercise for wages in Figure 5b. Wage polarization is also more pronounced for high routine share commuting zones, with steeper wage growth at both tails and shallower wage growth near the median.

The next sections present the detailed empirical analysis. Section 3.1 provides evidence on technology adoption and displacement of routine labor in local labor markets. Section 3.2 analyzes the determinants of rising low-skill service occupation employment within labor markets. Section 3.3 provides evidence on the broader pattern of employment and wage changes among low-skill workers in occupation groups with low and high routine intensities and also discusses the ensuing effects on 
labor mobility.

\subsection{PC adoption and displacement of routine labor}

While real cost of computing power has declined precipitously from the onset of the electronic computing era during the 1940s to the present, the rate of progress has varied substantially across decades. Nordhaus (2007, Table 8) estimates that the progress of computing decelerated in the 1960s and 1970s - when annual price declines slowed from approximately 45 percent in the 1940s and 1950s to as low as 22 percent per annum in the 1970s - and then accelerated sharply thereafter, with average cost declines averaging 60 to 70 percent per year during the period that is studied in this paper, i.e., the 1980s through the mid 2000s. The mechanism that links the declining price of computer capital to the polarization of local labor markets in our conceptual model is the substitution of information technology for labor in performing routine tasks. The model predicts that commuting zones with a greater initial routine employment share should differentially adopt information technology in response to its declining price and, by the same token, differentially displace labor from routine tasks.

We explore these implications, starting with computer adoption, by using a measure of geographic computer penetration developed by Doms and Lewis (2006) and also employed in Beaudry, Doms and Lewis (2010). Based on private sector surveys of computer inventories, this measure counts the number of personal computers per employee at the firm level, which is a relevant, albeit incomplete, measure of computer adoption. Doms and Lewis purge this measure of industry by establishmentsize fixed effects using a linear regression model and aggregate the adjusted variable to the level of local labor markets. We match the Doms and Lewis 'adjusted computers-per-worker' measure for the years 1990 and 2002 to commuting zones. ${ }^{33}$ Following the approach of Doms, Dunne and Troske (1997), we treat the 1990 level of this variable as the 'change' from 1980 to 1990, thus assuming that PC use was close to zero in all areas in 1980. We approximate the change in this variable over the subsequent decade using 5/6 of the 1990 to 2002 first-difference. ${ }^{34}$

We estimate models predicting computer adoption (PCs per worker) across commuting zones of the form:

$$
\Delta P C_{j s t}=\delta_{t}+\beta_{0} \times R S H_{j s t_{0}}+\gamma_{s}+e_{j s t},
$$

where the dependent variable is the change in the Doms-Lewis measure of computer adoption over decade $t_{0}$ to $t_{1}$ in commuting zone $j$ in state $s, R S H_{j s t_{0}}$ is that commuting zone's share of routine employment at the start of the decade, and standard errors are clustered at the state level. Due to the inclusion of a vector of state dummies $\gamma_{s}$, the coefficient of interest, $\beta$, is identified by withinstate cross-CZ variation. We estimate this model separately by decade and by pooling multiple decades as stacked first differences with an added time dummy.

\footnotetext{
${ }^{33}$ We thank Mark Doms and Ethan Lewis for providing us with this commuting zone-level data for 1990 and 2002. Approximately 50 of the 722 commuting zones do not have corresponding computer adoption data and so are dropped from the analysis. These commuting zones account for less than $1 \%$ of US population.

${ }^{34}$ The level of the PC-per-worker measure is not readily interpretable because it is a regression residual, as explained above. The cross commuting zone standard deviation of the change in this variable is 0.048 for 1980-1990 and 0.053 for 1990-2000.
} 
Table 3. Computer Adoption and Task Specialization within Commuting Zones, 1980 - 2005

Dependent Vars: $10 \times$ Annual Change in Adjusted PCs per Employee, $10 \times$ Annual Change in Employment Share of Routine Occupations

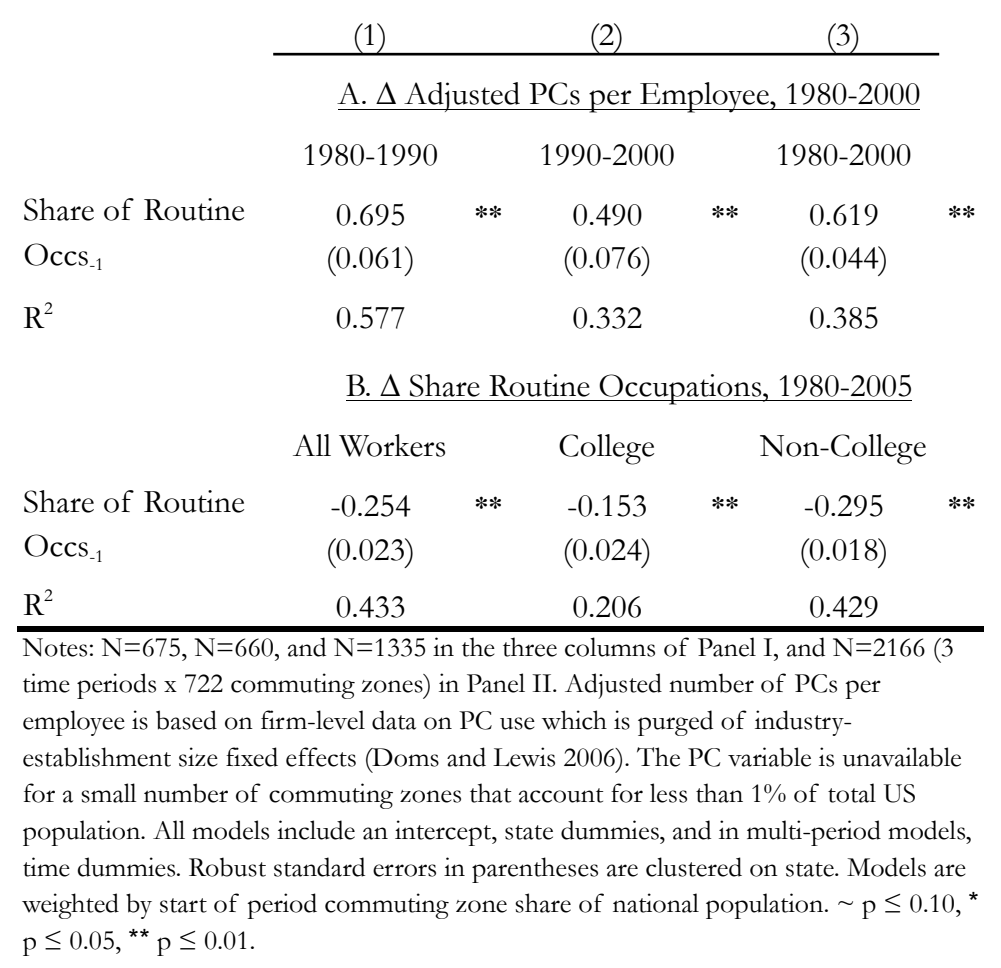

Estimates of this model in the upper panel of Table 3 confirm that the $R S H$ variable is highly predictive of computer adoption. The implied difference in computer adoption between the $80^{t h}$ and $20^{\text {th }}$ percentile commuting zone is economically large, equal in magnitude to approximately one full standard deviation of the computer adoption measure in each decade. ${ }^{35}$

The lower panel of Table 3 confirms that commuting zones with initially higher routine task specialization saw larger subsequent declines in routine-intensive occupations. Specifically, we regress changes in commuting zones' share of routine employment on their initial routine intensity, applying a stacked-first difference variant of equation (18) that pools three sets of changes: 1980-90, 1990-00, and 2000-05. The model in column (1) suggests that a commuting zone at the $80^{\text {th }}$ percentile of $1980 R S H$ experienced a 1.8 percentage points larger contraction of the routine occupation share per decade between 1980 and 2005 than did a $20^{\text {th }}$ percentile commuting zone. Consistent with the conceptual underpinnings of the model, columns 2 and 3 find that the decline in routine employment is substantially larger for non-college workers (high school or lower) than for college workers (at least one year of college). ${ }^{36}$

\footnotetext{
${ }^{35}$ Following Beaudry, Doms and Lewis (2010), we also estimated augmented models that control for the start-ofdecade skilled labor supply in each CZ, measured as the log ratio of college to non-college population. Consistent with their results, relative skill supply is a significant predictor of subsequent computer adoption, but the point estimate for the routine-share variable is only minimally affected by the addition of this measure. Results are available from the authors.

${ }^{36}$ Autor and Dorn (2009) further analyze the composition of employment gains in non-routine occupations. They
} 


\subsection{The growth of service occupation employment}

As shown above, the polarization of the U.S. employment distribution is substantially accounted for by rising employment in low skill service occupations. A key implication of the spatial equilibrium model is that this rapid rise in service employment should be most pronounced in initially routine task-intensive labor markets since the potential for displacement of non-college labor from routine activities is greatest in these locations.

The scatter plots in Figure 6 provide graphical evidence on this prediction. The upper panel of the figure depicts the bivariate relationship between initial commuting zone routine share, $R S H_{1980}$, and the change in the share of non-college labor employed in service occupations over the subsequent 25 years. Each plotted point represents one of 722 commuting zones, and the regression line corresponds to the following weighted OLS regression of the change in the service employment share on the initial $R S H$, where weights are equal to commuting zone shares of national population in 1980:

$$
\Delta S V C_{j, 1980-2005}=-0.0343+\begin{gathered}
0.336 \times R S H_{j, 1980} \\
(t=11.1)
\end{gathered} \quad \begin{array}{lll}
e_{j t} & \\
& R^{2}=0.27
\end{array}
$$

The explanatory power of this bivariate relationship is substantial. The coefficient of 0.336 on $R S H$ implies that a commuting zone with the mean routine share of 0.33 in 1980 is predicted to increase its share of non-college labor in service employment by 7.7 percentage points between 1980 and 2005, while the expected increase in non-college service employment in the commuting zone at the 80th percentile of $R S H$ is 3.2 percentage greater than in the 20th percentile commuting zone.

The lower panel of Figure 6 illustrates the geography of this relationship by plotting the relationship between initial routine share and the growth of service employment for the subsample of 64 commuting zones with populations over 750 thousand in 1980, where each commuting zone is identified by the name of its largest city. This figure underscores an important characteristic of initially routine occupation-intensive cities: they do not only comprise industrial cities such as Detroit or Newark, but also knowledge-intensive cities such as New York City and San Francisco. This pattern is consistent with the observation that routine-intensity is high in both production and clerical occupations (Table 2). Local labor markets with relatively low routine employment tend to be specialized in such industries as hospitality and tourist services (e.g., Orlando), education and health (e.g., Raleigh), or construction and mining (e.g., Houston).

\subsubsection{Service employment: Detailed OLS estimates}

Table 4 provides a longer-term perspective on the predictive relationship depicted in Figure 5 by regressing the change in the non-college service occupation share on the start of the period routine employment share by decade for the period 1950 through $2005 .{ }^{37}$

The relationship between the routine employment share and growth of service employment within commuting zones is only weakly evident prior to the 1980s and actually has the opposite sign during

find that declines in routine occupations within commuting zones are primarily offset by relative employment gains in low-skill, non-routine occupations - jobs that are on average significantly less skill-intensive and lower-paying than the routine occupations that are displaced. The gains in low-skill, non-routine occupations are substantially larger 
the 1950s and 1960s. The relationship becomes highly significant in the 1980s and its magnitude

for non-college than college-educated workers relative to their displacement from routine occupations.

${ }^{37}$ The lack of detailed geographic information in the 1960 Census prevents us from constructing commuting zones for this decade, and hence we analyze the 1950 to 1970 period as a single first difference. The dependent variable for 1950 to 1970 is divided by two and the dependent variable for 2000 to 2005 is multiplied by two to place them on the same decadal time scale. All models include state dummies.

Panel A

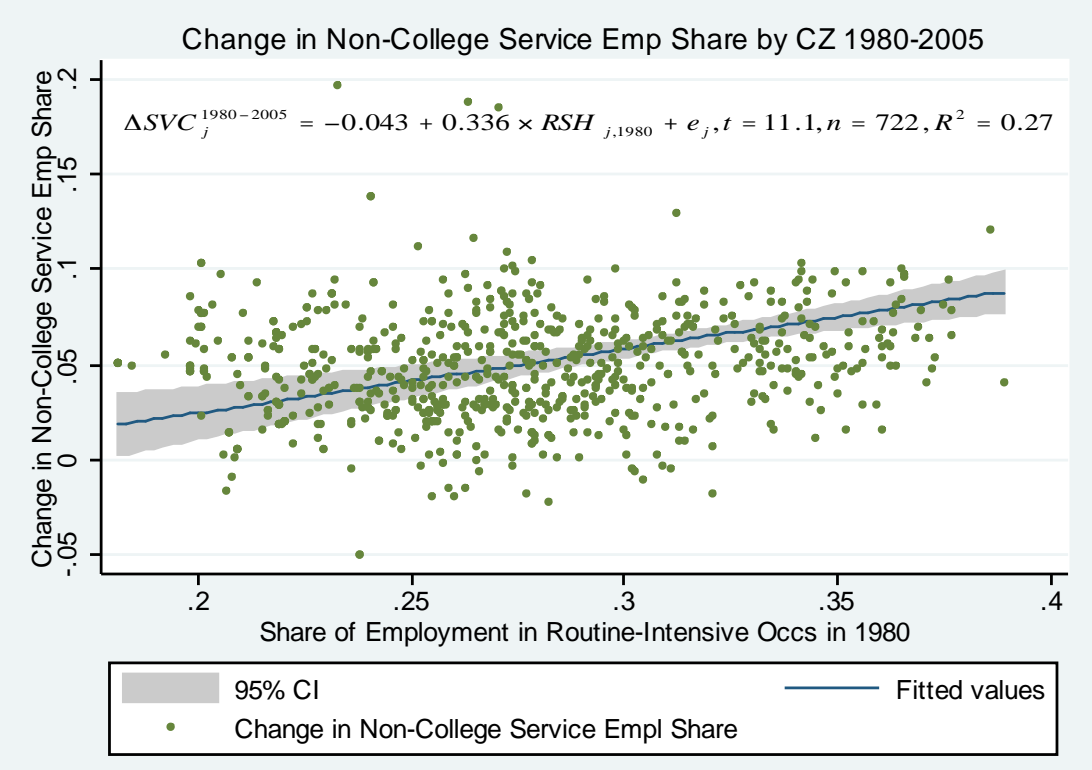

Panel B

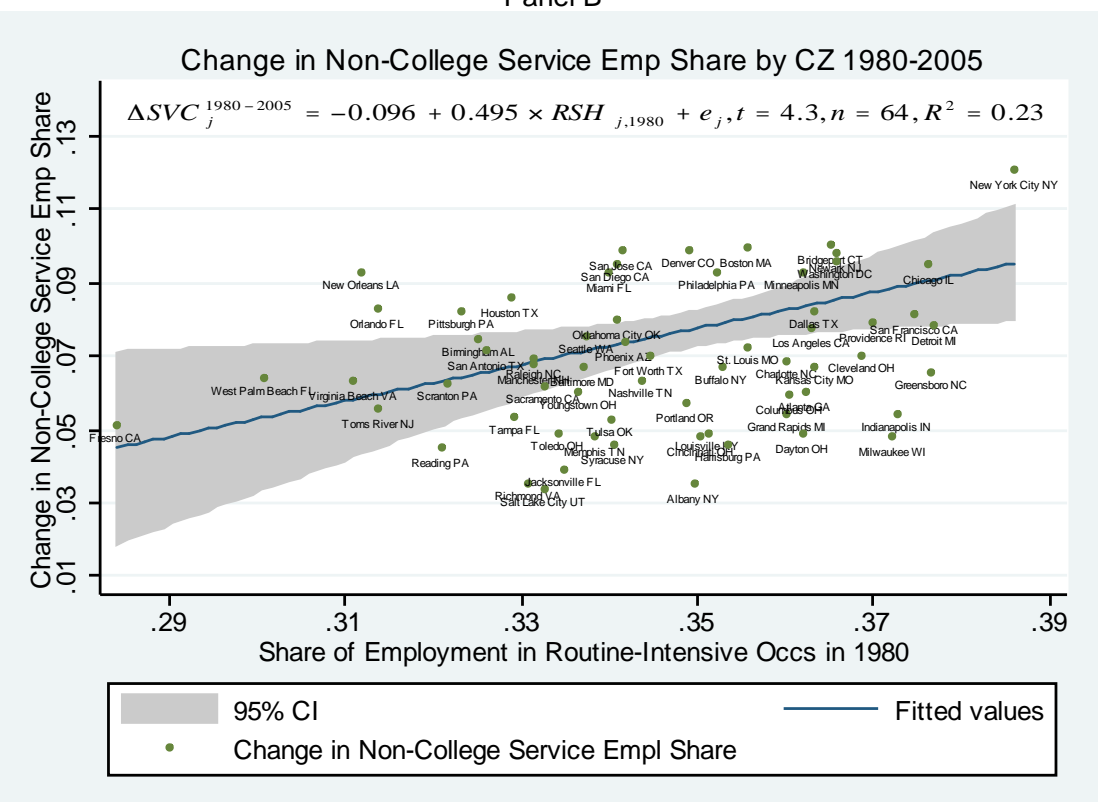

Figure 6.

Changes in Non-College Employment Share in Service Occupation, 1980-2005, vs. Routine Employment Share in 1980 for All Commuting Zones (Panel A) and Commuting Zones with >750,000 Residents (Panel B). 
Table 4. Routine Employment Share and Growth of Service Employment within Commuting Zones, 1950 - 2005

Dependent Variable: $10 \times$ Annual Change in Share of Non-College Employment in Service Occupations

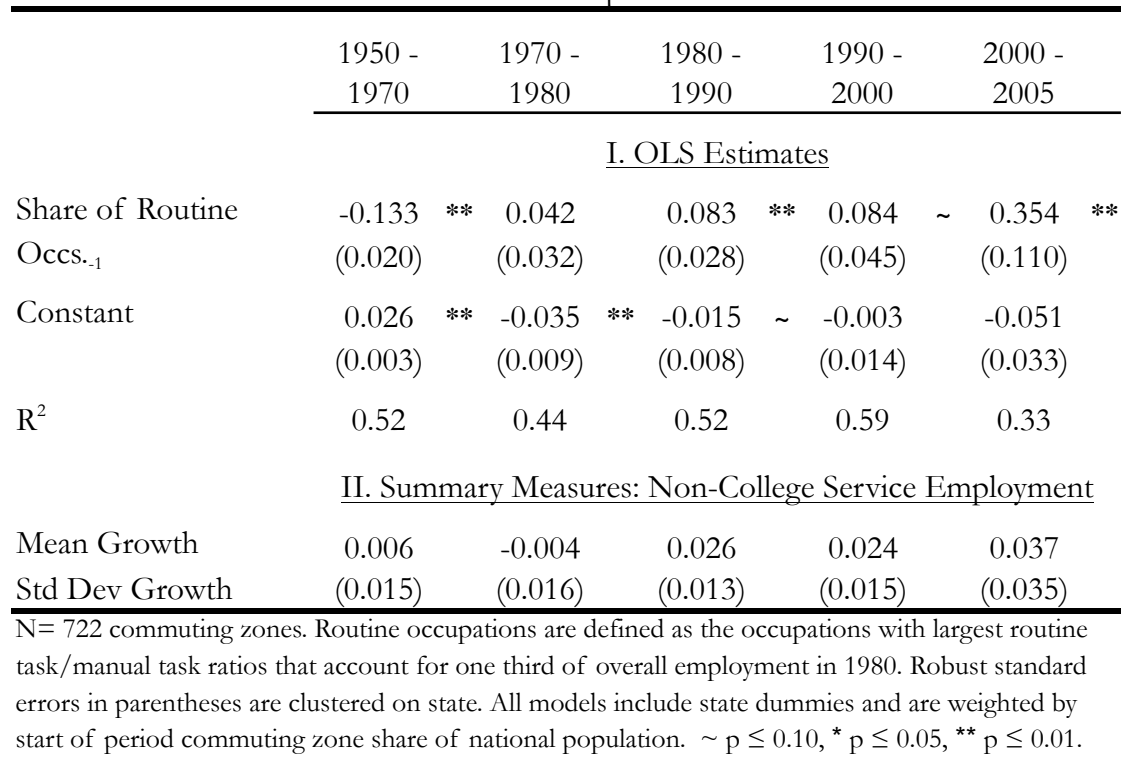

increases further in the 2000s. ${ }^{38}$

Alongside routine task-intensity, a host of human capital, demographic, and local labor market factors may explain differences across commuting zones in the growth of service employment. We consider these factors using an augmented version of equation (18):

$$
\Delta S V C_{j s t}=\delta_{t}+\beta_{1} R S H_{j t_{0}}+\beta_{2} X_{j t_{0}}+\gamma_{s}+e_{j s t},
$$

where $\Delta S V C_{j s t}$ is the change in the non-college service employment share in $\mathrm{CZ} j$ located in state $s$ between years $t_{0}$ and $t_{1}$, and $R S H_{j t_{0}}$ is the CZ's start of period routine-share. This equation stacks the three time periods covering the interval 1980 through 2005, and includes a full set of time period effects, state effects, as well as the start-of-period values of seven additional explanatory variables.

As a baseline, the first column presents a pooled specification with the routine share measure, time dummies, and state dummies. Columns 2 and 3 add two variables intended to capture shifts in the demand and supply for service occupations: the ratio of college to non-college educated individuals in the population (expressed in logarithms) and the share of the non-college population that is foreign born. These controls enter with the expected sign. Greater relative supply of collegeeducated individuals predicts rising service employment among non-college workers, as does a greater stock of foreign born residents (consistent with Cortes, 2008).

Column 4 considers two measures of local labor demand conditions: the unemployment rate and the share of employment in manufacturing. Service employment grows less rapidly in areas with higher unemployment and a larger manufacturing employment share.

\footnotetext{
${ }^{38}$ Farm-intensive commuting zones tended to have low levels of the $R S H$ in 1950 . The movement of labor from farm occupations into other low skill occupations in these CZs may potentially explain the negative relationship between the $R S H$ and growth of service employment in this period.
} 
Column 5 considers a pair of potential demand shifters: the elderly share of population and the female labor force participation rate. Since the elderly have high demand for specific services such as home health assistance, a greater share of senior citizens in the population may raise service employment. Likewise, many services, such as restaurant meals or housekeeping, serve as substitutes for household production. Hence, higher female labor force participation might be expected to raise demand for these services (Manning, 2004; Mazzolari and Ragusa, 2008). Surprisingly, neither of these predictions is born out by the data. Service employment appears to grow more rapidly in commuting zones with lower female labor force participation and a smaller elderly share. ${ }^{39}$

Since service occupations have the lowest wage levels of any major occupation group, their growth may also be affected by changes in the minimum wage. Column 6 explores the role of the minimum wage in service occupation employment by including a variable measuring the start-ofdecade fraction of non-college workers in a commuting zone whose real wage is below the minimum wage that will be enacted in the subsequent decade. ${ }^{40}$ Consistent with expectations, a larger fraction of workers for whom the minimum wage will become binding significantly dampens the growth of service occupation employment.

When the full set of explanatory variables is included in the model (column 7), the point estimate on the $R S H$ variable remains robustly significant and economically large. Recall that the 80/20 range of the routine share measure in 1980 is 0.07 . This translates into a difference of approximately 0.8 percentage point per decade in the growth of the non-college service employment in the $80^{\text {th }}$ versus $20^{\text {th }}$ percentile commuting zone relative to a mean decadal change of 2.9 percentage points over 1980 through 2005.

\subsubsection{Instrumental variables estimates}

Our estimates so far explore the relationship between the routine employment share in a $\mathrm{CZ}$ at the beginning of a decade and subsequent within-CZ changes in computer penetration, low-skill service employment, and routine-intensive employment. This approach raises the question of what causes $R S H$ to vary across commuting zones. Our theoretical model attributes this variation to stable differences in production structure across CZ's, but our empirical analysis has so far been agnostic on these empirical determinants, focusing primarily on what the variation is not (e.g., immigration, skill supply).

To see the problem this may pose, consider an augmented version of the simple estimation equation above (20) where we replace the variable $R S H_{j t_{0}}$ with two terms $R S H_{j}^{*}$ and $\nu_{j t_{0}}$ where $R S H_{j t_{0}}=R S H_{j}^{*}+\nu_{j t_{0}}$ :

$$
\Delta Y_{j s t}=\delta_{t}^{\prime}+\beta_{1}^{\prime} R S H_{j}^{*}+\beta_{2}^{\prime} \nu_{j t_{0}}+\gamma_{s}^{\prime}+\epsilon_{j s t}^{\prime}
$$

In this expression, $R S H_{j}^{*}$ represents the long-run, quasi-fixed component of industrial structure that is posited by our model to determine commuting zones' routine occupation shares. Conversely,

\footnotetext{
${ }^{39}$ When entered as decadal changes rather than lagged levels, both covariates enter with the expected sign: service employment grows when the elderly population share or female labor force participation rises.

${ }^{40}$ Statutory minimum wage levels by state and year are from Autor, Manning and Smith (2010).
} 
Table 5. Routine Employment Share and Growth of Service Employment within Commuting Zones, 1980 2005: Stacked First Differences: OLS and 2SLS Estimates

Dependent Variable: $10 \times$ Annual Change in Share of Non-College Employment in Service Occupations

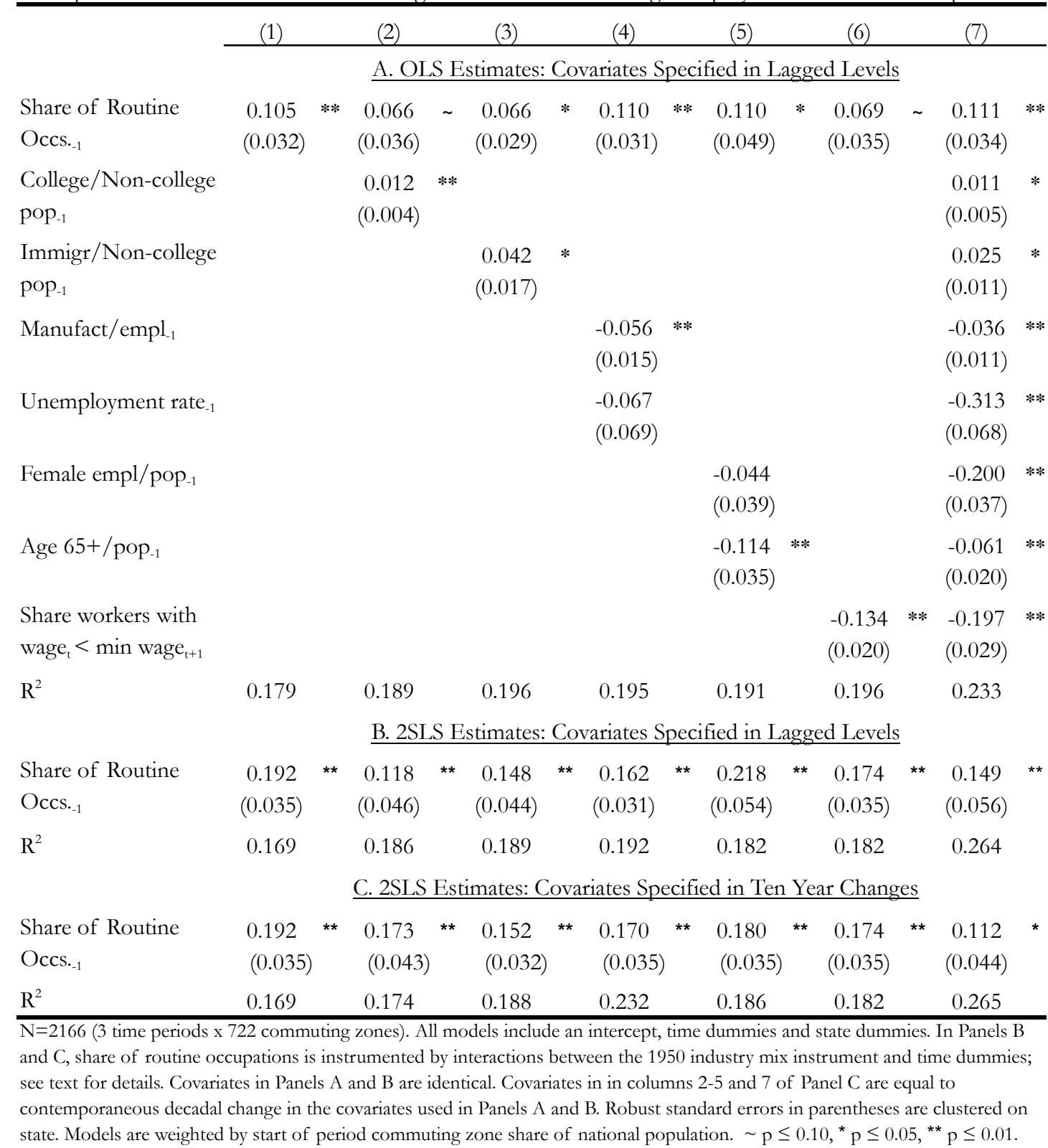

$\nu_{j t_{0}}$ is any unobserved, time-varying attribute that affects CZs' routine occupation shares and also influences $\Delta Y$ (i.e., if $\beta_{2}^{\prime} \neq 0$ ). For example, $\nu_{j t_{0}}$ might reflect a cyclical spike in the demand for a CZ's manufacturing outputs, which draws low-skilled workers temporarily from services into manufacturing (thus raising $R S H_{j t_{0}}$ relative to $R S H_{j}^{*}$ ). If present, this type of cyclical fluctuation would lead to biased OLS estimates of $\beta_{1}$ in equation (20) by inducing a positive relationship between the start of period level of $R S H$ and the subsequent change in $Y$ that is not caused by $R S H_{j}^{*}{ }^{41}$

To address this potential bias, we exploit historical cross-CZ differences in industry specialization

\footnotetext{
${ }^{41}$ Specifically, if $\beta_{2}^{\prime}>\beta_{1}^{\prime}\left(\beta_{2}^{\prime}<\beta_{1}^{\prime}\right)$ and $\operatorname{Var}(\nu)>0$, OLS estimates of $\beta_{1}$ will be upward (downward) biased.
} 
to isolate the long-run, quasi-fixed component of the routine occupation share, $R S H^{*}$. Our approach is as follows: let $E_{i j, 1950}$ equal the employment share of industry $i \in 1, \ldots, I$ in commuting zone $j$ in 1950 , and let $R_{i,-j, 1950}$ equal the routine occupation share among workers in industry $i$ in 1950 in all U.S. states except the state that includes commuting zone $j .{ }^{42}$ The product of these two measures provides a predicted value for the routine employment share in each commuting zone, which depends only on the local industry mix in 1950 and the occupational structure of industries nationally in 1950:

$$
\widetilde{R S H}_{j}=\sum_{i=1}^{I} E_{i, j, 1950} \times R_{i,-j, 1950} .
$$

This measure is a logical instrumental variable for $R S H$ : because it is determined three decades prior to 1980, we expect it to be correlated with the long-run component of the routine occupation share $R S H^{*}$ but uncorrelated with contemporaneous innovations to $R S H$ reflected in $\nu$.

Appendix Table 3 presents first-stage estimates for this instrumental variables model. The predictive relationship between $\widetilde{R S H}$ and $R S H$ is sizable and highly significant, with t-ratios of six or above in each decade. The first stage coefficient is close to unity in 1950, and takes smaller values in successive periods, obtaining a coefficient of 0.27 in $2000{ }^{43}$ The decrease in magnitude is to be expected since initial conditions become less determinative over time. The second row of the table presents a pooled model that includes all decades of data and adds time dummies and a full set of interactions between the $\widetilde{R S H}_{j}$ measure and these dummies. Point estimates for the coefficients of interest in the pooled regression are similar in magnitude and significance to the by-decade estimates.

Using the 2SLS model, the second panel of Table 5 repeats our main estimates for the growth of non-college service employment. These 2SLS estimates are precisely estimated and are typically somewhat larger in magnitude than their OLS counterparts. In the most complete specification (column 7), the 2SLS point estimate is 0.149 versus 0.111 in the OLS model, and both are statistically significant.

As a further test of the robustness of the predictive relationship between the routine-employment share and the reallocation of non-college labor into service occupations, the third panel of Table 5 repeats the 2SLS estimates while entering the human capital, labor market, and demographic variables as contemporaneous changes rather than start of period levels. This approach is arguably unduly conservative in that these contemporaneous outcomes-such as unemployment and declining manufacturing-may themselves result from technological displacement of routine-intensive occupations. Nonetheless, the coefficient on the routine share variable is precisely estimated and comparable in magnitude to the prior specification. ${ }^{44}$

\footnotetext{
${ }^{42}$ Following Autor and Duggan (2003), we exclude own state employment from the construction of our instrument for local labor market conditions to remove any mechanical correlation between the instrument and the endogenous variable. Throughout the analysis, we implicitly consider commuting zones to be part of the state that contains the largest share of their population.

${ }^{43}$ The predictive relationship in 1950 does not have to equal unity since only out-of-state variation in occupational composition within industries is used to predict the routine share in each commuting zone.

${ }^{44}$ To conserve space, we do not tabulate the level or change covariates in panels B and C. The coefficients on the level controls in panels $\mathrm{A}$ and $\mathrm{B}$ are highly comparable. The coefficients on the change controls in panel $\mathrm{C}$ are all statistically significant and each has the expected sign: positive for college/non-college population, immigrants/noncollege population, unemployment rate, elderly share of population, female labor force participation; negative for
} 
We have performed many additional tests to probe the generality and robustness of the main results for computer adoption, decline of routine employment, and growth in low-skill service employment. We obtain qualitatively similar findings when estimating the models in Tables 3 and 4 using 2SLS in place of OLS, when fitting separate models for large (population $>250 \mathrm{~K}$ in 1980) and small (population $\leq 250 K$ in 1980) commuting zones, and when estimating models for the decline in routine-intensive employment and growth of service employment separately by sex. ${ }^{45}$ In addition, Appendix Table 4 fits 2SLS models for the relationship between the routine employment share and changes in non-college employment in nine subgroups of service occupations: food service, cleaning and gardening, health support, child care, personal appearance, security guards, recreation, and miscellaneous services. The positive relationship between RSH and service employment growth is present both in female-dominated service occupations that provide substitutes for home production (e.g., child care workers and hairdressers) and in typically male-dominated service jobs (e.g., janitors and security guards). The point estimates are positive for eight of nine service occupation categories and are statistically significant at $p \geq 0.10$ in six.

\subsubsection{Alternative hypotheses}

In addition to the demographic and local labor market factors considered in Table 5, three other potential explanations for the rise of service employment in routine-intensive local labor markets merit careful study. These are: (1) growing offshoring (rather than automation) of job tasks, which displaces low skill workers into non-offshorable service occupations; (2) rising income at the top of the wage distribution, which stimulates demand for in-person services among wealthy households (an income effect, as in Clark 1957); and (3) rising returns to skill, which spur college-educated workers to increase labor supply and substitute market for home-based production of household services (Manning, 2004, Ngai and Pissarides, 2008, and Mazzolari and Ragusa, 2008). This subsection investigates these three mechanisms and finds little evidence that they are empirically important drivers of polarization - at least at the level of local labor markets. ${ }^{46}$

An expanding literature studies the growth of international offshoring, whereby firms carry out specific subcomponents (or tasks) of their production processes abroad (e.g., Feenstra and Hanson 1999, Grossman and Rossi-Hansberg 2008, Blinder 2009, Blinder and Krueger 2009, Firpo, Fortin and Lemieux 2011, and Jensen and Kletzer, forthcoming). Papers in this literature observe that the occupational tasks most suitable for offshoring are those that can be performed effectively without physical proximity to customers or specific worksites. Many of the routine tasks in production and clerical occupations appear to meet these criteria. By contrast, the job tasks performed in service occupations are typically poorly suited to offshoring as many require face-to-face interactions between workers and customers (e.g., hairdressers and waiters) or direct physical access to the customer's work site (i.e., cleaners and security guards). This reasoning suggests that offshoring could explain the growth of low skill service employment rather than (or in addition to) the automation of routine

manufacturing employment share. Full results are available from the authors.

${ }^{45}$ Detailed results are available from the authors.

${ }^{46}$ Goos, Manning and Salomons (2011) reach a similar conclusion in their cross-national analysis. 
tasks.

Unlike trade in goods, the offshoring of job tasks is not included in national accounts and hence is largely unmeasured. We follow the standard approach in the literature of measuring the offshoring potential ('offshorability') of job tasks rather than the actual offshoring that occurs. To operationalize offshorability, we use a simple average of the two variables Face-to-Face Contact and On-Site Job that Firpo, Fortin and Lemieux (2011) derive from U.S. Department of Labor's Occupational Information Network database $\left(\mathrm{O}^{*} \mathrm{NET}\right)$. This measure captures the degree to which an occupation requires either direct interpersonal interaction or proximity to a specific work location. ${ }^{47}$ The commuting zone level offshorability index is equal to the average offshorability score of employment in each commuting zone and year, and is further normalized to have a mean of zero and a cross commuting zone standard deviation of one in 1980. We find a substantial correlation between routine employment shares and offshorability across commuting zones $(\rho=0.66) .{ }^{48}$

The first panel of Table 6 tests whether commuting zones with higher start-of-period offshorability experienced differential growth of service employment among non-college workers between 1980 through 2005. Column 1 finds the expected positive relationship between offshorability and the subsequent growth of low skill service employment, but the point estimate is statistically insignificant and small in magnitude. Column 2 adds the routine share measure to the model. This variable is robustly predictive of service employment growth and its magnitude is little affected by inclusion of the offshorability index (compare column 1B of Table 5). With this variable included, the offshorability measure reverses sign while remaining insignificant.

We have verified the robustness of this basic pattern of results to many plausible permutations of this specification: allowing the start-of-period routine occupation share and the offshorability index to each take separate slopes in the final decade of the sample; controlling for the contemporaneous change in manufacturing employment; and additionally allowing the slope on the manufacturing measure to differ in the final decade. In all cases, we find a positive, significant, and robust relationship between the routine share and the reallocation of non-college labor into service employment. ${ }^{49}$ Our findings here are in line with other recent work that finds that offshorability plays a relatively minor explanatory role when considered alongside other potential causes (particularly, routine job task content) in explaining cross-industry and cross-national trends in employment or wage polarization (Goos, Manning and Salomons 2010, Michaels, Natraj and Van Reenen 2010). ${ }^{50}$

\footnotetext{
${ }^{47}$ We reverse the sign of the measure so that it is increasing rather than decreasing in offshorability. By this metric, the five least offshorable occupations are respiratory therapists, dentists, fire fighters, elevator installers, and podiatrists while the most offshorable occupations are clothing pressing machine operators, weighers, statisticians, operations researchers, and financial records processing clerks. Further detail are provided in the supplementary appendix.

${ }^{48}$ Blinder (2009) notes that the clearly defined procedures of routine tasks may make them particularly prone to offshoring but argues that the overlap between routine content and offshoring potential is incomplete. Blinder and Krueger (2009) find that their survey measures of offshorability and 'routinizability' are essentially orthogonal.

${ }^{49}$ In these models, the offshoring variable has a marginally significant positive relationship with service employment growth in the final decade, but this is not robust to inclusion of the routine share measure. The contemporaneous decline in manufacturing employment in the final decade of the sample (an outcome variable) also predicts a significant rise in non-college service employment, but controlling for this measure has little effect on the routine share variable. Detailed results are available from the authors.

${ }^{50}$ An exception is Firpo, Fortin and Lemieux (2011), who estimate that offshoring contributed to wage polarization
} 
Table 6. Predicting Changes in Service Occupation Employment with Measures of Offshorability, Income Effects, and Substitution Effects.

Dependent Variable: $10 \times$ Annual Change in Share of Non-College Employment in Service Occs, 1980 - 2005

\begin{tabular}{|c|c|c|c|c|c|c|c|c|}
\hline & \multicolumn{2}{|c|}{ A. Offshoring } & \multicolumn{2}{|c|}{ B. Income Effects } & \multicolumn{4}{|c|}{ C. Substitution Effects } \\
\hline & (1) & $(2)$ & (3) & (4) & (5) & (6) & $(7)$ & $(8)$ \\
\hline Share of Routine Occs $_{-1}$ & & $\begin{array}{l}0.164 * * \\
(0.044)\end{array}$ & & $\begin{array}{l}0.205 * * \\
(0.037)\end{array}$ & & $\begin{array}{l}0.209 * * \\
(0.037)\end{array}$ & $\begin{array}{l}0.215 * * \\
(0.038)\end{array}$ & $\begin{array}{l}0.181 * * \\
(0.035)\end{array}$ \\
\hline Offshorability Index $_{-1}$ & $\begin{array}{c}0.007 \\
(0.005)\end{array}$ & $\begin{array}{l}-0.005 \\
(0.006)\end{array}$ & & & & & & \\
\hline$\Delta \ln ($ P90) Weekly Wage & & & $\begin{array}{c}0.013 \\
(0.015)\end{array}$ & $\begin{array}{l}-0.017 \\
(0.015)\end{array}$ & & & & \\
\hline $\begin{array}{l}\Delta \text { Avg Annual Hours per } \\
\text { Coll Grad / } 2080\end{array}$ & & & & & $\begin{array}{l}-0.111 * \\
(0.032)\end{array}$ & $\begin{array}{l}-0.127 * * \\
(0.031)\end{array}$ & & \\
\hline $\begin{array}{l}\Delta \text { Avg Annual Hours per } \\
\text { Male Coll Grad / } 2080\end{array}$ & & & & & & & $\begin{array}{l}-0.069 * * \\
(0.018)\end{array}$ & \\
\hline $\begin{array}{l}\Delta \text { Avg Annual Hours per } \\
\text { Female Coll Grad / } 2080\end{array}$ & & & & & & & & $\begin{array}{l}-0.083 * * \\
(0.024)\end{array}$ \\
\hline $\mathrm{R}^{2}$ & 0.17 & 0.18 & 0.17 & 0.17 & 0.19 & 0.19 & 0.18 & 0.19 \\
\hline
\end{tabular}

The next two panels of Table 6 explore the potential contribution of income and substitution effects among high skill workers to rising service employment by augmenting the baseline regression model with two additional explanatory variables. To capture wage structure shifts that may generate income effects, we use changes in the $90^{t h}$ percentile of the log weekly wage distribution among fulltime, full-year workers in the CZ. To measure shifts in the labor supply of high skill workers that may generate substitution effects that increase service demand, we use changes in mean annual hours worked by college graduates in the CZ. ${ }^{51}$

Consistent with expectations, both top wages and college graduate hours per workers rose by significantly more in routine-employment intensive commuting zones between 1980 and 2005.52 Nevertheless, these proxies for income and substitution effects do not have a strong direct relationship with growth in service employment. A rise in the $90^{t h}$ percentile of weekly wages is only weakly correlated with rising service employment, and this relationship turns negative when the routine share is included (panel B). ${ }^{53}$ Rising annual work hours among college graduates is negatively re-

among U.S. males between 2003 and 2009.

${ }^{51}$ Because this measure includes hours worked of all working-age college graduates independent of their labor force status, it captures changes at both the intensive and extensive margin of labor supply.

${ }^{52}$ Regression estimates imply that the commuting zone at the 80 th percentile of RSH in 1980 experienced 9 additional log points per decade rise in the $90^{t h}$ percentile of full-time, full-year wage and 16 additional hours per decade increase in annual labor supply of college graduates relative to the $20^{\text {th }}$ percentile commuting zone over the 1980 through 2005 period. Both relationships are statistically significant. The correlation coefficient between $\mathrm{RSH}$ and the change in the $90^{t h}$ percentile of earnings is 0.29 while the correlation between RSH and the change in college labor supply is 0.16 . A full table of results is available from the authors.

${ }^{53}$ Our findings are qualitatively identical if we instead use the $75^{\text {th }}$ wage percentile or the mean log weekly wage of 
lated to service employment growth, a pattern that holds whether we measure college labor overall or separately by gender (panel C). Notably, the routine share variable remains highly predictive of rising service employment and is essentially unaffected by inclusion of these controls.

\subsection{Employment and wage changes in major occupation groups}

The final empirical section broadens the focus of the analysis beyond service occupation employment to consider the relationship between routine employment intensity and changes in non-college employment and wages across all six major occupation groups summarized in Table 1. The spatial model predicts that polarization of both employment and wages should be more pronounced in routine task-intensive labor markets. We have so far verified this prediction for employment in service occupations but have not considered either service occupation wages or employment and wage changes elsewhere in the occupational distribution. Table 7 takes up this task, beginning in panel A with changes in non-college employment by major occupational category.

Although service occupations stand apart in both their low routine task content and rapid employment growth since 1980, two other major occupation groups are also characterized by relatively low routine task content: blue-collar transportation, construction, mechanical, mining, and farm occupations; and white-collar managerial, professional, technical, finance, and public safety occupations. Notably, the share of non-college employment accounted for by these occupations expanded modestly between 1980 and 2005 (Appendix Table 1).

The first three columns of Table 7 estimate the relationship between the routine employment share and the growth of non-college employment in these three non-routine-intensive occupations. The first cell in column 1 repeats the earlier 2SLS estimate for non-college service employment (compare column 1B of Table 5). The next two rows highlight that the differential reallocation of non-college labor into service occupations in CZs with high routine employment is equally pronounced for men and women. Thus, this pattern is not gender-specific. Columns 2 and 3 display analogous models for non-college employment in the two other non-routine-intensive occupation groups. Consistent with the pattern for service employment (though less pronounced), the noncollege employment share differentially increases in both of these occupations in routine-intensive local labor markets between 1980 and $2005 .^{54}$

The next three columns of Table 7 repeat these estimates for three broad occupational categories that are relatively high in routine task content: clerical, administrative support, and retail sales occupations; precision production and craft occupations; and machine operator and assembler occupations. The estimates demonstrate that non-college employment differentially contracted in all of these occupational categories in routine-intensive commuting zones between 1980 and 2005. The employment share declines were particularly pronounced in productive and operator occupations among males, and in clerical and sales occupations among females.

\footnotetext{
college graduates. Results are available from the authors.

${ }^{54}$ Note that the white-collar non-routine occupation category in column 3 of Table 8 is numerically small because this group of occupations employs primarily college workers.
} 


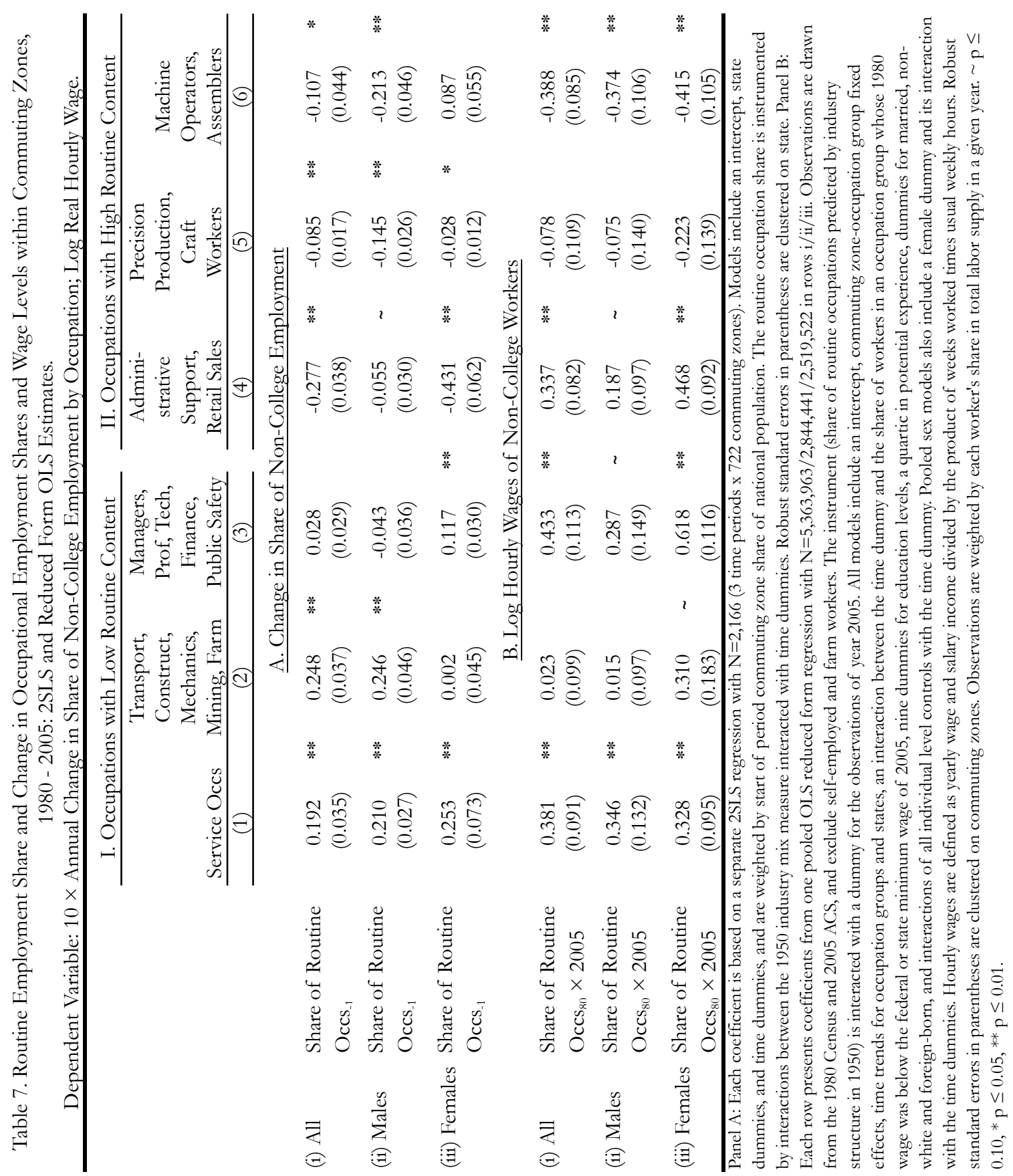

We next consider whether there were differential wage changes among non-college workers in routine-intensive labor markets. We pool microdata on the log hourly wages of non-college workers from the 1980 Census and the 2005 American Community Survey to estimate a set of 2SLS wage equations of the following form:

$$
\ln w_{i j s k t}=\gamma_{j k}+\lambda_{k}\left\{R S H_{j, 1980} \times 1[t=2005]\right\}+X_{i}^{\prime} \beta_{t}+\delta_{k t}+\phi_{s t}+e_{i j k t},
$$

where $i$ denotes workers, $j$ denotes commuting zones, $s$ denotes states, $k$ denotes occupations, and $t$ denotes time $(1980,2005)$. The term $\lambda_{k}\left\{R S H_{j, 1980} \times 1[t=2005]\right\}$ interacts the (instrumented) 
start-of-period routine employment share variable with the 2005 dummy and thus measures, separately for each occupation group, the impact of a CZ's routine-intensity in 1980 on wage growth during 1980 to 2005. The wage equation also includes commuting zone and time dummies which are interacted with occupation dummies, and a set of worker-level covariates and state dummies, each interacted with time dummies. ${ }^{55}$ Hourly wages are deflated by the national Personal Consumption Expenditure deflator, which does not account for local or regional price levels. Standard errors are clustered at the commuting zone level since the main predictive variable, $R S H$, does not vary within commuting zones. ${ }^{56}$

Panel B of Table 7 presents the wage estimates. For non-college workers of both sexes, hourly wages in service occupations rise by significantly more in CZs with a relatively high routine share. A 7 percentage point higher routine share in 1980 , equal to the gap between the $80^{\text {th }}$ and $20^{\text {th }}$ percentile commuting zones, predicts approximately 3 log points greater wage growth in service occupations between 1980 and 2005. We also find uniformly positive wage effects for the two other occupation categories with low routine task content in columns 2 and 3 of Panel B, though not all individual point estimates are significant. In sum, the three occupation groups with low routine content experience differential growth in non-college employment and wages in initially routine-intensive local labor markets.

The wage estimates for occupations with high routine content present a mixed picture. For operative and assembler occupations, the estimated wage effects are robustly negative and comparable in magnitude (but opposite in sign) to the estimates for service occupations, as predicted by the task framework. For precision production and craft occupations, wage estimates are uniformly negative but are not precisely estimated. For clerical, administrative support and retail sales occupations, the pronounced decrease in employment found in Panel A coincides with an unexpected increase in wages comparable in size and significance to the column (1) point estimates for service occupations. The fact that clerical employment and wages are moving strongly in countervailing directions in routine-intensive labor markets - opposite to the pattern for the five other occupations in Table 7 - provides no conclusive evidence for falling demand for these occupations, and weakens our wage results overall.

As discussed in section 2.2, a potential interpretation of the wage trends in clerical occupations is that as traditional clerical tasks have succumbed to automation, the work content of the remaining clerical and administrative jobs has become concentrated in more skill-demanding, less routineintensive tasks. Consistent with this observation, we note that the occupation-level correlation between employment and wage growth in 1980 to 2005, which is positive in the overall sample, is significantly negative among clerical and sales occupations, a pattern that is not observed for any other occupation group. This negative correlation suggests that observed wage growth in clerical occupations is likely not due to rising demand for these jobs (which would tend to raise employment along with wages) but rather due to selection, i.e., the least skilled and most routine-intensive

\footnotetext{
${ }^{55}$ Redundant interaction terms are dropped (e.g., with a complete set of CZ dummies, only one set of state by time dummies is retained).

${ }^{56}$ Wages in farm occupations are excluded because they are unreliable.
} 
activities within clerical occupations are displaced, while more skilled and less routine-intensive clerical activities persist. This mechanism is consistent with the Roy component of our theoretical model, whereby self-selection induces the workers who are most productive in routine tasks to remain in goods production. Nevertheless, a lack of consistent time-series data on task changes within occupations prevents a full test of this hypothesis. ${ }^{57}$

With the caveats above, these results broadly establish that routine task-intensive labor markets saw rising employment and earnings of non-college workers in non-routine intensive occupations combined with declining employment, and in some cases declining wages, in routine-intensive occupations. ${ }^{58}$ Among all occupational categories, service occupations stand out for sharp gains in employment shares and wages among non-college workers, consistent with the hypothesis that local demand has shifted in favor of this occupational category.

Complementing these findings, we show in Online Appendix Table 2 that local labor markets that are intensive in routine employment also experience greater polarization of educational attainment during the same period. Specifically, the proportions of both college graduates and high school dropouts increase relative to the fractions of workers with some college or with high school education in these markets. Similarly, recent migrants into these markets are substantially more likely to be college graduates than are incumbent residents, and to a lesser degree are also more likely to be high school dropouts. In combination with the Table 7 results, this mobility evidence suggests that labor demand differentially increased between 1980 and 2005 for both the highest and lowest skilled occupations in routine employment-intensive labor markets.

\section{Conclusions}

While the past 25 years have seen stagnant or declining real earnings and employment of most low skill occupations, employment and earnings in service occupations offer a striking exception. Between 1980 and 2005, the share of hours worked in service occupations among non-college workers rose by more than 50 percent. Simultaneously, real hourly wages of non-college workers in service occupations increased by 11 log points, considerably exceeding wage growth in other low skill occupations. This phenomenon is broadly important because it offers insight into the polarization of employment and earnings in the U.S. and, potentially, other industrialized countries. Indeed, a key fact documented by this paper is that rising employment and wages in service occupations account for a substantial share of aggregate polarization and growth of the lower tail of the U.S. employment and earnings distributions between 1980 and 2005.

\footnotetext{
${ }^{57}$ Autor, Levy and Murnane (2003, Table VI) construct measures of changes in task content within occupations using successive editions of the Dictionary of Occupational Titles, though, as they note, a substantial fraction of DOT occupations is not updated. Their analysis nevertheless documents a very pronounced decline in routine task content in occupations undergoing rapid computer adoption and, moreover, that this change in task content is not captured by changes occupations' educational composition.

${ }^{58}$ We have estimated analogous wage models for each decade between 1980 and 2005 and obtain the same qualitative pattern of results: CZ's with a higher $R S H$ experienced in each decade greater relative wage gains in service, managerial, professional and technical, and transportation and construction occupations than in production and craft and operative and assembler occupations.
} 
This paper proposes an integrated explanation and conducts a detailed empirical analysis of the forces behind the changing shape of low education, low wage employment in the U.S. labor market. We hypothesize that recent computerization has substituted for low skill workers in performing routine tasks while complementing the abstract, creative, problem-solving, and coordination tasks performed by highly-educated workers. As the declining price of computer technology has driven down the wage paid to routine tasks, low skill workers have reallocated their labor supply to service occupations, which are difficult to automate because they rely heavily on dexterity, flexible interpersonal communication, and direct physical proximity. Our conceptual model shows that if the demand for these service outputs does not admit close substitutes, then substitution of information technology for routine tasks used in goods production can induce rising wages and employment in low skill service occupations. This hypothesis builds on Baumol's (1967) model of unbalanced technological progress by broadening it to the study of skill demands and wage structure (in addition to Baumol's focus on sectoral composition).

Motivated by the observation that workers in service occupations must collocate with demanders of their services, we extend the model to a spatial equilibrium setting and develop empirical implications that we test at the level of 722 consistently defined commuting zones encompassing the entirety of the U.S. mainland. The model predicts that commuting zones that were initially relatively intensive in routine job activities - that is, tasks that became cheap and easy to computerize in recent decades - should have exhibited differential changes in the structure of local production along four dimensions: (1) greater adoption of information technology; (2) greater reallocation of low skill workers from routine task-intensive occupations into service occupations (i.e., employment polarization); (3) larger increases in both employment and wages at both ends of the occupational skill distribution (i.e., wage polarization); (4) and larger net inflows of both high and low skill labor attracted by these demand shifts.

In bringing the model to the data, we measure commuting zones' specialization in routine taskintensive employment by mapping task data from the Dictionary of Occupational Titles to occupation data from the Census. We instrument this task-based measure using the interaction between commuting zones' historical industry structures and the national occupational composition of these industries (both measured in 1950). The variation in routine task intensity across commuting zones proves robustly predictive of the changes in task and wage structure implied by the model, including: adoption of information technology; reallocation of labor activity away from routine tasks; employment and wage growth in low skill service occupations; and inward mobility of high and low skill labor.

Alongside our primary hypothesis of unbalanced technological progress, we consider a panoply of alternative explanations including offshoring of jobs tasks, income and substitution effects in high skill consumption and labor supply, and demographic and economic shifts including immigration, population aging, female labor force entry, and declining manufacturing employment. Many of these alternative explanations receive some empirical support but none appears to play a leading role. Moreover, none would appear conceptually suited to explain the totality of the evidence presented. 
The consequences of employment and wage polarization for skill demands, earnings levels, and job composition are only beginning to receive academic study (e.g., Levy and Murnane, 2004; U.S. National Research Council, 2008). Our results suggest a critical role for changes in labor specialization, spurred by automation of routine task activities, as a driver of rising employment and wage polarization in the U.S. and potentially in other countries.

\section{References}

Acemoglu, Daron. 1999. "Changes in Unemployment and Wage Inequality: An Alternative Theory and Some Evidence." American Economic Review, 89 (December), 1259-1278.

Acemoglu, Daron. 2002. "Technical Change, Inequality, and the Labor Market." Journal of Economic Literature, 40, 7-72.

Acemoglu, Daron and David H. Autor. 2010. "Skills, Tasks and Technologies: Implications for Employment and Earnings." in O. Ashenfelter and D. Card, eds. Handbook of Labor Economics, Volume 4.

Acemoglu, Daron, David H. Autor, and David Lyle. 2004. "Women, War, and Wages: The Effect of Female Labor Supply on the Wage Structure at Mid-Century." Journal of Political Economy, $112(3), 497-551$.

Acemoglu, Daron and Veronica Guerrieri. 2007. "Capital Deepening and Nonbalanced Economic Growth." Journal of Political Economy, 116(3), 467-498.

Armington, Paul S. 1969. "A Theory of Demand for Products Distinguished by Place and Production." International Monetary Fund Staff Papers, XVI, 159-178.

Autor, David H. and David Dorn. 2009. "This Job is "Getting Old: Measuring Changes in Job Opportunities using Occupational Age Structure." American Economic Review Papers and Proceedings, 99(2), 45-51.

Autor, David H. and Mark G. Duggan. 2003. "The Rise in the Disability Rolls and the Decline in Unemployment." Quarterly Journal of Economics, 118(1), February, 157-206.

Autor, David H., Lawrence F. Katz, and Melissa S. Kearney. 2006. "The Polarization of the U.S. Labor Market." American Economic Review, 96:2 (May), 189-194.

Autor, David H., Lawrence F. Katz, and Melissa S. Kearney. 2008. "Trends in U.S. Wage Inequality: Revising the Revisionists." Review of Economics and Statistics. 90(2), May, 300-323.

Autor, David H., Frank Levy, and Richard J. Murnane. 2003. "The Skill Content of Recent Technological Change: An Empirical Investigation." Quarterly Journal of Economics, 118(4), November, 1279-1333.

Autor, David H., Alan Manning, and Christopher L. Smith. 2010. "The Contribution of the Minimum Wage to U.S. Wage Inequality over Three Decades: A Reassessment." NBER Working Paper No. 16533, November.

Bartel, Ann, Casey Ichniowski and Kathryn Shaw. 2007. "How Deos Information Technology Affect Productivity? Plant-Level Comparisons of Product Innovation, Process Improvement, and Workers Skills." Quarterly Journal of Economics, 122(4), November, 1721-1758.

Baumol, William J. 1967. "Macroeconomics of Unbalanced Growth: Anatomy of an Urban Crisis." American Economic Review, 57(3), June, 415-426.

Beaudry, Paul, Mark E. Doms, and Ethan G. Lewis. 2010. "Should the Personal Computer Be Considered a Technological Revolution? Evidence from U.S. Metropolitan Areas." Journal of Political Economy, 118(5), 988-1036. 
Blanchard, Olivier Jean and Lawrence F. Katz. 1992. "Regional Evolutions." Brookings Papers on Economic Activity, 1992(1), 1-75.

Blinder, Alan S. 2009. "How Many US Jobs Might Be Offshorable?" World Economics, 10(2), 41-78.

Blinder, Alan S. and Alan B. Krueger. 2009. "Alternative Measures of Offshorability: A Survey Approach." NBER Working Paper No. 15287, August.

Bound, John and Harry J. Holzer. 2000. "Demand Shifts, Population Adjustments, and Labor Market Outcomes during the 1980s." Journal of Labor Economics, 18(1), 20-54.

Card, David and Thomas Lemieux. 2001. "Can Falling Supply Explain the Rising Return to College for Younger Men? A Cohort-Based Analysis." Quarterly Journal of Economics, 116, 705 746.

Clark, Colin. 1957. The Conditions of Economic Progress. London: Macmillan.

Cortes, Patricia. 2008. "The Effect of Low-Skilled Immigration on U.S. Prices: Evidence from CPI Data." Journal of Political Economy, 116(3), 381-422.

DiNardo, John E., Nicole M. Fortin, and Thomas Lemieux. 1996. "Labor Market Institutions and the Distribution of Wages, 1973-1992: A Semiparametric Approach." Econometrica, 64(5), 1001-1044.

Doms, Mark E., Timothy Dunne, and Kenneth R. Troske. 1997. "Workers, Wages, and Technology." Quarterly Journal of Economics, 112(1), 253-290.

Doms, Mark E. and Ethan G. Lewis. 2006. "Labor Supply and Personal Computer Adoption." Federal Reserve Bank of Philadelphia Working Paper No. 06-10, June.

Dorn, David. 2009. "Essays on Inequality, Spatial Interaction, and the Demand for Skills." Dissertation University of St. Gallen no. 3613, September.

Ellison, Glenn and Edward L. Glaeser. 1997. "Geographic Concentration in U.S. Manufacturing Industries: A Dartboard Approach." Journal of Political Economy, 105(4), October, 889-927.

Feenstra, Robert, and Gordon H. Hanson. 1999. "The Impact of Outsourcing and HighTechnology Capital on Wages: Estimates for the U.S., 1972-1990." Quarterly Journal of Economics, 114(3), August, 907-940.

Firpo, Sergio, Nicole Fortin and Thomas Lemieux. 2011. "Occupational Tasks and Changes in the Wage Structure." Mimeo, University of British Columbia, February.

Glaeser, Edward L., and Joshua D. Gottlieb. 2009. "The Wealth of Cities: Agglomeration Economies and Spatial Equilibrium in the United States." Journal of Economic Literature, 47(4), December, 983-1028.

Goldin, Claudia and Lawrence Katz. 2008. The Race between Education and Technology. Cambridge: Harvard University Press.

Goos, Maarten and Alan Manning. 2007. "Lousy and Lovely Jobs: The Rising Polarization of Work in Britain." Review of Economics and Statistics 89 (February), 118-133.

Goos, Maarten, Alan Manning, and Anna Salomons. 2009. "Recent Changes in the European Employment Structure: The Roles of Technology and Globalization." American Economic Review Papers and Proceedings, 99(2), May, 58-63.

Goos, Maarten, Alan Manning, and Anna Salomons. 2010. "Explaining Job Polarization in Europe: The Roles of Technology and Globalization." Katholieke Universiteit Leuven Working Paper, May.

Grossman, Gene M. and Esteban Rossi-Hansberg. 2008. "Trading Tasks: A Simple Theory of Offshoring." American Economic Review, 98(5): 1978-1997.

Hecker, Daniel E. 2005. "Occupational Employment Projections to 2014." Monthly Labor Review, 128(11): 70-101. 
Jensen, J. Bradford and Lori Kletzer. forthcoming. "Measuring Tradable Services and the Task Content of Offshorable Services Jobs." in Labor in the New Economy, Katharine Abraham, Mike Harper and James Spletzer (eds.), Chicago: University of Chicago Press.

Katz, Lawrence F. and David H. Autor. 1999. "Changes in the Wage Structure and Earnings Inequality." in O. Ashenfelter and D. Card, eds. Handbook of Labor Economics, Volume 3, Amsterdam: Elsevier.

Katz, Lawrence F. and Kevin Murphy. 1992. "Changes in Relative Wages, 1963-1987: Supply and Demand Factors." Quarterly Journal of Economics, 107(1), February, 35-78.

Krugman, Paul. 1991. "Increasing Returns and Economic Geography." Journal of Political Economy, 99(3), 483-499.

Lefter, Alexandru and Benjamin M. Sand. 2011. "Job Polarization in the U.S.: A Reassessment of the Evidence from the 1980s and 1990s." University of St. Gallen Working Discussion Paper no. 2011-03, February.

Levy, Frank and Richard J. Murnane. 2004. The New Division of Labor. New Jersey, Princeton University Press.

Manning, Alan. 2004. "We Can Work it Out: the Impact of Technological Change on the Demand for Low-Skill Workers." Scottish Journal of Political Economy, 51(5), November, 581-608.

Mazzolari, Francesca and Giuseppe Ragusa. 2008. "Spillovers from High-Skill Consumption to Low-Skill Labor Markets." Mimeograph, University of California at Irvine, May.

Meyer, Peter B. and Anastasiya M. Osborne. 2005. "Proposed Category System for 1960-2000 Census Occupations." Bureau of Labor Statistics Working Paper 383, September.

Michaels, Guy, Ashwini Natraj, and John Van Reenen. 2010. "Has ICT Polarized Skill Demand? Evidence from Eleven Countries over 25 years." NBER Working Paper No. 16138, June.

Moretti, Enrico. 2008 "Real Wage Inequality." NBER Working Paper No. 14370, September.

Ngai, L. Rachel and Christopher Pissarides. 2007. "Structural Change in a Multisector Model of Growth." American Economic Review, 97(1), March, 429-443.

Ngai, L. Rachel and Christopher Pissarides. 2008. "Trends in Hours and Economic Growth." Review of Economic Dynamics, 11, April, 239-256.

Nordhaus, William D. 2007. "Two Centuries of Productivity Growth in Computing." Journal of Economic History, 67(1), March, 128-159.

Notowidigdo, Matthew J. 2010. "The Incidence of Local Labor Demand Shocks." MIT working paper, January.

Pinker, Steven. 2007. The Stuff of Thought: Language as a Window into Human Nature. New York: Viking Adult (Penguin).

Ruggles, Steven, Matthew Sobek, Trent Alexander, Catherine A. Fitch, Ronald Goeken, Patricia Kelly Hall, Miriam King, and Chad Ronnander. 2004. Integrated Public Use Microdata Series: Version 3.0 [Machine-readable database]. Minneapolis, MN: Minnesota Population Center [producer and distributor].

Tolbert, Charles M. and Molly Sizer Killian. 1987. "Labor Market Areas for the United States." Staff Report No. AGES870721. Washington, DC: Economic Research Service, U.S. Department of Agriculture.

Tolbert, Charles M. and Molly Sizer. 1996. "U.S. Commuting Zones and Labor Market Areas. A 1990 Update." Economic Research Service Staff Paper No. 9614.

Topel, Robert H. 1986. "Local Labor Markets." Journal of Political Economy, 94(3), S111-S143.

U.S. Department of Labor, Employment and Training Administration. 1977. Dictionary of Occupational Titles: Fourth Edition (Washington, DC: US Government Printing Office).

U.S. Department of Labor, Occupational Outlook Handbook, 1976-1977 Edition, Bulletin 1875, 1976. 
U.S. Department of Labor, Occupational Outlook Handbook, 2000-2001 Edition, Bulletin 2520, 2000 .

U.S. National Research Council. 2008. "Research on Future Skill Demands: A Workshop Summary." Margaret Hilton, Rapporteur, Washington D.C.: The National Academies Press.

Weiss, Matthias. 2008. "Skill-biased Technical Change: Is There Hope for the Unskilled?" Economics Letters, 100(3), September, 439-441.

\section{Appendix Tables for "The Growth of Low Skill Service Jobs and the Polarization of the U.S. Labor Market"}

Appendix Table 1. Levels and Changes in Employment Share and Mean Real Log Hourly Wages by Major Occupation Groups among Workers without College Education, 1950-2005

\begin{tabular}{|c|c|c|c|c|c|c|c|c|}
\hline & \multicolumn{6}{|c|}{ Level } & \multicolumn{2}{|c|}{ Growth Rate (\%) } \\
\hline & 1950 & 1970 & 1980 & 1990 & 2000 & 2005 & $1950-80$ & $1980-05$ \\
\hline \multicolumn{9}{|c|}{ A. Share of Employment (\%pts) } \\
\hline Managers/Prof/Tech/Finance/Public Safety & 14.5 & 13.4 & 14.5 & 15.9 & 14.2 & 15.0 & -0.1 & 3.9 \\
\hline Production/Craft & 5.7 & 5.7 & 6.0 & 4.9 & 5.5 & 4.5 & 6.1 & -25.8 \\
\hline Transport/Construct/Mech/Mining/Farm & 33.8 & 27.8 & 29.5 & 29.2 & 30.2 & 31.3 & -12.7 & 6.2 \\
\hline Machine Operators/Assemblers & 14.8 & 17.1 & 14.7 & 12.5 & 10.4 & 8.5 & -0.8 & -42.5 \\
\hline Clerical/Retail Sales & 19.1 & 22.6 & 22.4 & 22.0 & 21.8 & 20.9 & 17.7 & -6.6 \\
\hline Service Occupations & 12.2 & 13.3 & 12.9 & 15.6 & 17.9 & 19.8 & 5.8 & 53.2 \\
\hline \multicolumn{9}{|c|}{ B. Mean Log Hourly Wage (2004\$) } \\
\hline Managers/Prof/Tech/Finance/Public Safety & 2.12 & 2.69 & 2.64 & 2.59 & 2.68 & 2.76 & 17.4 & 4.8 \\
\hline Production/Craft & 2.25 & 2.72 & 2.71 & 2.65 & 2.63 & 2.63 & 15.5 & -3.1 \\
\hline Transport/Construct/Mech/Mining/Farm & 2.04 & 2.56 & 2.59 & 2.51 & 2.56 & 2.57 & 18.4 & -0.9 \\
\hline Machine Operators/Assemblers & 2.03 & 2.46 & 2.46 & 2.42 & 2.47 & 2.48 & 14.2 & 0.7 \\
\hline Clerical/Retail Sales & 1.96 & 2.39 & 2.37 & 2.35 & 2.41 & 2.45 & 13.5 & 3.1 \\
\hline Service Occupations & 1.45 & 2.00 & 2.07 & 2.09 & 2.17 & 2.18 & 20.6 & 4.2 \\
\hline
\end{tabular}


Appendix Table 2. Rankings of Occupations with Highest and Lowest Routine Intensity

\begin{tabular}{|c|c|c|}
\hline $\begin{array}{l}\text { A. Occupations with } \\
\text { Highest RTI Scores }\end{array}$ & $\begin{array}{l}\text { B. Low-Skill Occupations } \\
\text { with Lowest RTI Scores }\end{array}$ & $\begin{array}{l}\text { C. High-Skill Occupations } \\
\text { with Lowest RTI Scores }\end{array}$ \\
\hline 1 Butchers \& meat cutters & 1 Bus drivers & 1 Fire fighting, prevention $\&$ inspection \\
\hline 2 Secretaries \& stenographers & 2 Taxi cab drivers \& chauffeurs & 2 Police \& detectives, public service \\
\hline 3 Payroll \& timekeeping clerks & 3 Waiters \& waitresses* & 3 Primary school teachers \\
\hline 4 Bank tellers & 4 Truck, delivery, \& tractor drivers & 4 Managers of properties \& real estate \\
\hline 5 File clerks & 5 Door-to-door/street sales, news vendors & 5 Secondary school teachers \\
\hline 6 Cashiers & 6 Carpenters & 6 Electrical engineers \\
\hline 7 Typists & 7 Telecom \& line installers \& repairers & 7 Physicians \\
\hline 8 Pharmacists & 8 Housekeepers, maids, butlers \& cleaners* & 8 Computer systems analysts \& scientists \\
\hline 9 Bookkeepers, accounding clerks & 9 Health \& nursing aides* & 9 Civil engineers \\
\hline \multicolumn{2}{|c|}{10 Postal clerks, except mail carriers 10 Electricians } & 10 Industrial engineers \\
\hline \multicolumn{3}{|c|}{$\begin{array}{l}\text { Notes: Asterisk denotes low-skill service occupations. The Routine Task Index (RTI) is defined as RTI }=\ln (\mathrm{R}) \ln (\mathrm{M}) \text {-ln }(\mathrm{A}) \text { where R, M, and A are } \\
\text { occupation-level measures for routine, manual, and abstract tasks derived from the Dictionnary of Occupational Titles (DOT) 1977. Low-skill } \\
\text { occupations in Panel B include occupations in which the share of workers without college education is larger than in the overall workforce in 1980; } \\
\text { high-skill occupations in Panel B include occupations with a below-average share of non-college workers. All occupations in Panel A except } \\
\text { secretaries and pharmacists are low-skill occupations according to this definition. For occupations with equal RTI score, ranking ties are split by } \\
\text { giving a higher ranking to the occupation with larger share in total US employment in 1980. The ranking includes all occupations whose employment } \\
\text { share is at least half as large as the employment share of the average occupation, and excludes agricultural, supervisory and residual occupations. }\end{array}$} \\
\hline
\end{tabular}

Appendix Table 3. First Stage Estimates of Models for Routine Occupation Share Measure. Dependent variable: Routine Occupation Share in Commuting Zones in Indicated Years

\begin{tabular}{|c|c|c|c|c|c|c|c|c|c|c|}
\hline \multirow[b]{3}{*}{$\begin{array}{l}1950 \text { Industry Mix } \\
\text { Measure }\end{array}$} & 1950 & & 1970 & & 1980 & & 1990 & & \multicolumn{2}{|l|}{2000} \\
\hline & \multicolumn{10}{|c|}{ I. Single Decade Regressions } \\
\hline & $\begin{array}{c}1.055 \\
(0.082)\end{array}$ & $* *$ & $\begin{array}{c}0.624 \\
(0.062)\end{array}$ & $* *$ & $\begin{array}{c}0.521 \\
(0.063)\end{array}$ & & $\begin{array}{c}0.353 \\
(0.055)\end{array}$ & $* *$ & $\begin{array}{c}0.272 \\
(0.047)\end{array}$ & $* *$ \\
\hline \multirow[t]{2}{*}{$\mathrm{R}^{2}$} & 0.793 & & 0.697 & & 0.656 & & 0.530 & & 0.480 & \\
\hline & \multicolumn{10}{|c|}{ II. Pooled Regression, 1950-2005 } \\
\hline $\begin{array}{l}1950 \text { Industry Mix } \\
\text { Measure }\end{array}$ & $\begin{array}{c}1.066 \\
(0.082)\end{array}$ & $* *$ & $\begin{array}{c}0.663 \\
(0.059)\end{array}$ & $* *$ & $\begin{array}{c}0.542 \\
(0.060)\end{array}$ & & $\begin{array}{c}0.328 \\
(0.053)\end{array}$ & $* *$ & $\begin{array}{c}0.230 \\
(0.047)\end{array}$ & $* *$ \\
\hline $\mathrm{R}^{2}$ & & & & & & & & & 0.802 & \\
\hline
\end{tabular}


Appendix Table 4. Routine Employment Share and Growth of Employment in Detailled Service Occupations within Commuting Zones, 1980 - 2005: Stacked First Differences (2SLS Estimates).

Dependent Variable: $10 \times$ Annual Change in Share of Non-College Employment in Specific Service Occupation

\begin{tabular}{|c|c|c|c|c|c|c|c|c|c|c|}
\hline & $\begin{array}{c}\text { Food } \\
\text { Service }\end{array}$ & & $\begin{array}{l}\text { Building } \\
\text { Clean/ } \\
\text { Garden }\end{array}$ & $\begin{array}{l}\text { Health } \\
\text { Support }\end{array}$ & $\begin{array}{l}\text { House } \\
\text { Clean/ } \\
\text { Laundry }\end{array}$ & $\begin{array}{l}\text { Child } \\
\text { Care }\end{array}$ & $\begin{array}{c}\text { Personal } \\
\text { Appear- } \\
\text { ance }\end{array}$ & $\begin{array}{l}\text { Security } \\
\text { Guards }\end{array}$ & $\begin{array}{c}\text { Recreat- } \\
\text { ion }\end{array}$ & $\begin{array}{c}\text { Misc } \\
\text { Personal } \\
\text { Svcs } \\
\end{array}$ \\
\hline & \multicolumn{10}{|c|}{ A. Estimates } \\
\hline $\begin{array}{l}\text { Share of } \\
\text { Routine } \mathrm{Occs}_{-1}\end{array}$ & $\begin{array}{l}0.073 \\
(0.015)\end{array}$ & $* *$ & $\begin{array}{l}0.051 * * \\
(0.017)\end{array}$ & $\begin{array}{c}0.003 \\
(0.017)\end{array}$ & $\begin{array}{l}0.012 \\
(0.010)\end{array}$ & $\begin{array}{l}0.009 \\
(0.005)\end{array}$ & $\begin{array}{r}\sim \\
\sim \\
(0.017 \\
\end{array}$ & $\begin{array}{ll}* & 0.019 \\
& (0.006)\end{array}$ & $\begin{array}{ll}* * & 0.010 \\
& (0.006)\end{array}$ & $\begin{array}{r}\sim-0.002 \\
(0.004)\end{array}$ \\
\hline Constant & $\begin{array}{l}-0.009 \\
(0.005)\end{array}$ & $\sim$ & $\begin{array}{l}-0.007 \\
(0.006)\end{array}$ & $\begin{array}{l}0.004 \\
(0.005)\end{array}$ & $\begin{array}{l}-0.006 \\
(0.003)\end{array}$ & $\begin{array}{r}-0.002 \\
(0.002)\end{array}$ & $\begin{array}{l}-0.006 \\
(0.002)\end{array}$ & $\begin{aligned} * * & -0.005 \\
& (0.002)\end{aligned}$ & $\begin{array}{r}*-0.004 \\
(0.002)\end{array}$ & $\begin{array}{l}* 0.002 \\
(0.001)\end{array}$ \\
\hline \multirow[t]{2}{*}{$\mathrm{R}^{2}$} & 0.10 & & 0.27 & 0.13 & 0.10 & 0.17 & 0.10 & 0.08 & 0.23 & 0.12 \\
\hline & \multicolumn{10}{|c|}{ B. Descriptive Statistics: Employment Shares (Non-College Employment) } \\
\hline Emp 2005 & $6.55 \%$ & & $4.69 \%$ & $3.04 \%$ & $1.86 \%$ & $1.00 \%$ & $0.94 \%$ & $0.88 \%$ & $0.43 \%$ & $0.44 \%$ \\
\hline Emp 1980 & $4.18 \%$ & & $3.11 \%$ & $1.88 \%$ & $1.41 \%$ & $0.51 \%$ & $0.75 \%$ & $0.63 \%$ & $0.15 \%$ & $0.31 \%$ \\
\hline$\Delta 1980-2005$ & $2.37 \%$ & & $1.58 \%$ & $1.15 \%$ & $0.44 \%$ & $0.49 \%$ & $0.19 \%$ & $0.25 \%$ & $0.28 \%$ & $0.13 \%$ \\
\hline
\end{tabular}




\section{Data Appendix for "The Growth of Low Skill Service Jobs and the Polarization of the U.S. Labor Market"}

\section{Measuring labor supply and earnings}

Our sample of workers consists of individuals who were between age 16 and 64 and who were working in the year preceding the survey. Residents of institutional group quarters such as prisons and psychiatric institutions are dropped along with unpaid family workers. Labor supply is measured by the product of weeks worked times usual number of hours per week. For individuals with missing hours or weeks, labor supply weights are imputed using the mean of workers in the same educationoccupation cell, or, if the education-occupation cell is empty, the mean of workers in the same education cell. All calculations are weighted by the Census sampling weight multiplied by the labor supply weight and the weight derived from the geographic matching process that is described below.

The computation of wages excludes self-employed workers and individuals with missing wages, weeks or hours. Hourly wages are computed as yearly wage and salary income divided by the product of weeks worked and usual weekly hours. Top-coded yearly wages are multiplied by a factor of 1.5 and hourly wages are set not to exceed this value divided by 50 weeks times 35 hours. Hourly wages below the first percentile of the national hourly wage distribution are set to the value of the first percentile. The computation of full-time full-year weekly wages is based on workers who worked for at least 40 weeks and at least 35 hours per week. Wages are inflated to the year 2004 using the Personal Consumption Expenditure Index in order to be comparable to those of the 2005 ACS (which collects earnings in the prior year).

\section{Matching Census geography to commuting zones (CZs)}

We matched geographic information that is available in the Census Public Use samples to CZ geography. The most disaggregated geographic unit reported in the Census samples since 1990 is the Public Use Micro Area (PUMA). A PUMA is a subarea of a state that comprises a population of 100,000 to 200,000 persons but otherwise has no inherent economic interpretation. The 2000 Census splits the entire land area of the U.S. into more than 2,000 of these PUMAs.

The Census Bureau reports how the population of a PUMA is distributed over counties. If a PUMA overlaps with several counties, our procedure is to match PUMAs to counties assuming that all residents of a PUMA have equal probability of living in a given county. The aggregation of counties to CZs allows us to compute the probability that a resident of a given PUMA falls into a specific CZ. Many PUMAs (e.g., 81 percent of those in the 2000 Census) match fully into a single $\mathrm{CZ}$, while observations from the remaining PUMAs are proportionally assigned to several CZs. This geographic matching technique allows us to calculate the population characteristics of residents of each CZ consistently in each year of our data.

The Census Public Use files for the years prior to 1990 identify subareas of states called County Groups (in 1970 and 1980) or State Economic Areas (in 1950). These geographic units have a similar structure to PUMAs except that they do not provide a detailed within-county breakdown 
of the most populous counties. They are matched to CZs using the same procedure as outlined for PUMAs above. The 1960 Census files are not suitable for an analysis at the detailed geographic level because they provide no geographic information below the level of states.

\section{Building consistent occupations}

The Census classification of occupations changed over time, particularly between 1970 and 1980 and between 1990 and 2000. We use a slightly modified version of the crosswalk developed by Meyer and Osborne (2005) to create time-consistent occupation categories. Our classification creates a balanced panel of 330 occupations for the years 1980 to 2005 that allows us to follow a consistently defined set of occupations over time. The occupation categories of the 1950 to 1970 Census are also matched to this occupation system but not all 330 occupations are observed in every year.

The designation of occupations as "service occupations" is based on the occupational classification of the 2000 Census. We subdivide service occupations into nine groups: food preparation and service workers; building and grounds cleaning workers and gardeners; health service support workers (such as health and nursing aides, but excluding practical or registered nurses); protective service workers; housekeeping, cleaning and laundry workers; personal appearance workers (such as hairdressers and estheticians); child care workers; recreation and hospitality workers (such as guides, baggage porters, or ushers); and other personal service workers. Protective service occupations are further subdivided into policemen, fire fighters, and guards. Because police officers and firefighters have much higher educational attainment and wage levels than all other service workers, we consistently exclude them from our primary definition of service occupations. All other occupations are grouped into five broad categories that each are relatively homogeneous in their task content (see Tables 1 and 2): Whitecollar managerial, professional, technical, finance, and public safety occupations typically employ highly educated workers specializing in abstract job tasks; blue-collar transportation, construction, mechanical, mining, and farm occupations are rich in manual job tasks; while the three remaining occupations categories which are specialized in routine job tasks are: clerical, administrative support, and retail sales occupations; precision production and craft occupations; and machine operator and assembler occupations. Details of the construction of the occupational classification and a full list of the resulting 330 occupations are given in Dorn (2009). ${ }^{59}$

\section{Matching tasks to occupations}

Measures for abstract, routine and manual tasks are derived from the US Department of Labor's Dictionary of Occupational Titles (US Department of Labor, 1977; 'DOT' hereafter) and matched to

\footnotetext{
${ }^{59}$ Lefter and Sand (2011) identify several flaws in the Meyer-Osborne (2005) occupation coding scheme, implemented in the IPUMS samples, which can lead to misleading inferences about employment trends in a small number of low wage occupations. These flaws are also identified and corrected by Dorn (2009), and the corrections are implemented in the current paper.
} 
their corresponding Census occupation classifications. Following Autor, Katz and Kearney (2006), we collapse the original five task measures of Autor, Levy and Murnane (2003) to three task aggregates: the manual task measure corresponds to the DOT variable measuring an occupation's demand for "eye-hand-foot coordination;" the routine task measure is a simple average of two DOT variables, "set limits, tolerances and standards," measuring an occupation's demand for routine cognitive tasks, and "finger dexterity," measuring an occupation's use of routine motor tasks; and the abstract task measure is the average of two DOT variables: "direction control and planning," measuring managerial and interactive tasks, and "GED Math," measuring mathematical and formal reasoning requirements. Further details on these variables are found in Appendix Table 1 of Autor, Levy and Murnane (2003).

The measure for offshorability of occupations is derived from O*NET data, which are available for download at http://online.onetcenter.org/. We use a simple average of the two aggregate variables face-to-face contact and on-site job, and reverse the sign of the resulting variable so that it measures offshorability instead of non-offshorability. Firpo, Fortin and Lemieux (2011) define face-to-face contact as the average value of the $\mathrm{O}^{*} \mathrm{NET}$ variables "face-to-face discussions," "establishing and maintaining interpersonal relationships," "assisting and caring for others," "performing for or working directly with the public," and "coaching and developing others." They define on-site job as the average of the $\mathrm{O}^{*}$ Net variables "inspecting equipment, structures, or material," "handling and moving objects," "operating vehicles, mechanized devices, or equipment," and the mean of "repairing and maintaining mechanical equipment" and "repairing and maintaining electronic equipment." 


\section{Supplemental Appendix Tables for "The Growth of Low Skill Service Jobs and the Polarization of the U.S. Labor Market"}

Online Appendix Table 1. Routine Employment Share and Growth of Service Employment within Commuting Zones, 1980 - 2005: Stacked First Differences (2SLS Estimates) Robustness Checks.

Dependent Variable: $10 \times$ Annual Change in Share of Non-College Employment in Service Occupations

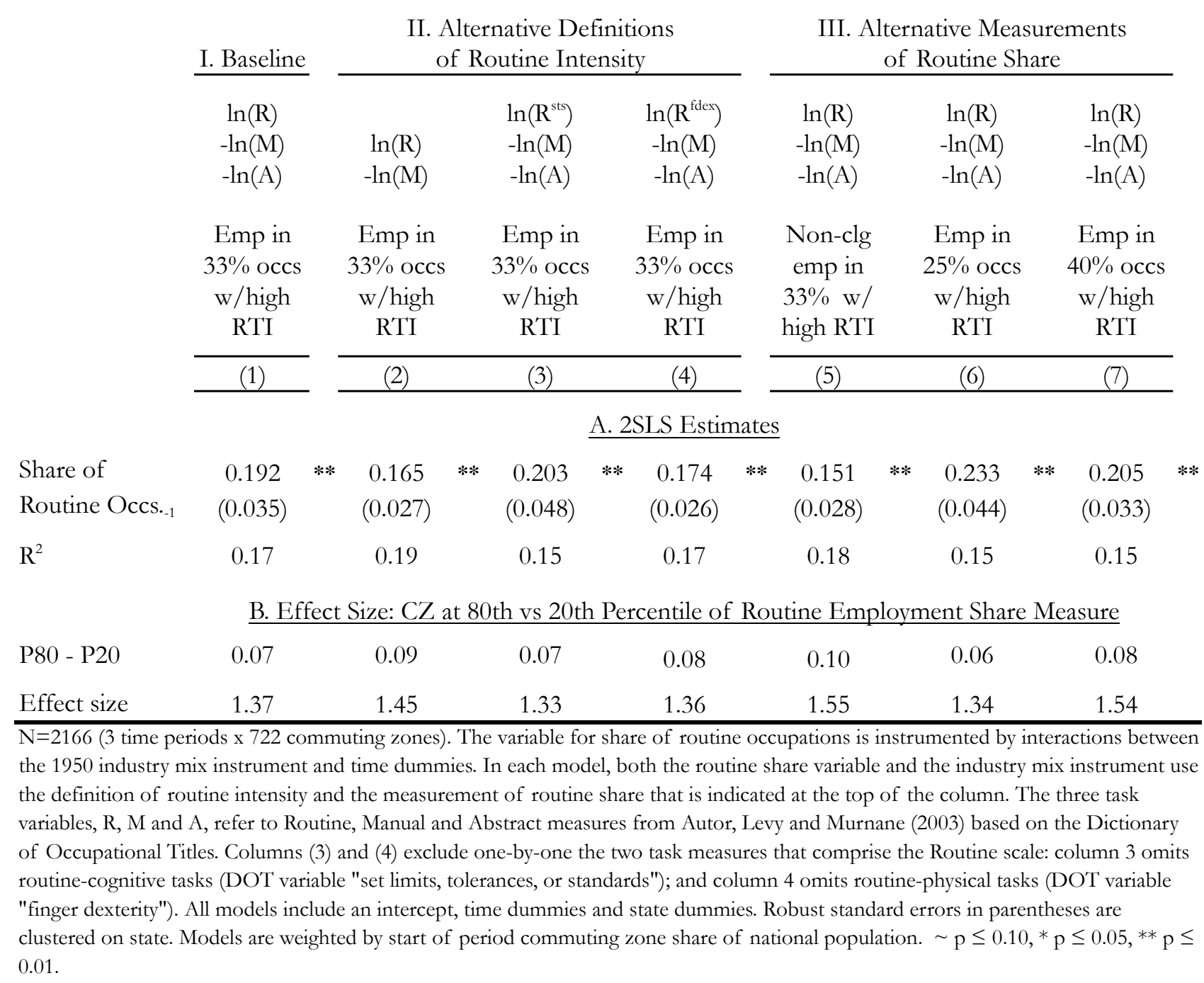


Online Appendix Table 2. Changes in Educational Composition, 1980-2005

(2SLS Estimates). Dependent Variable: $10 \times$ Annual Change in Education Shares; Difference in Education Shares between Migrant Workers (Out-of-State Five Years Ago) and Non-Migrant Workers.

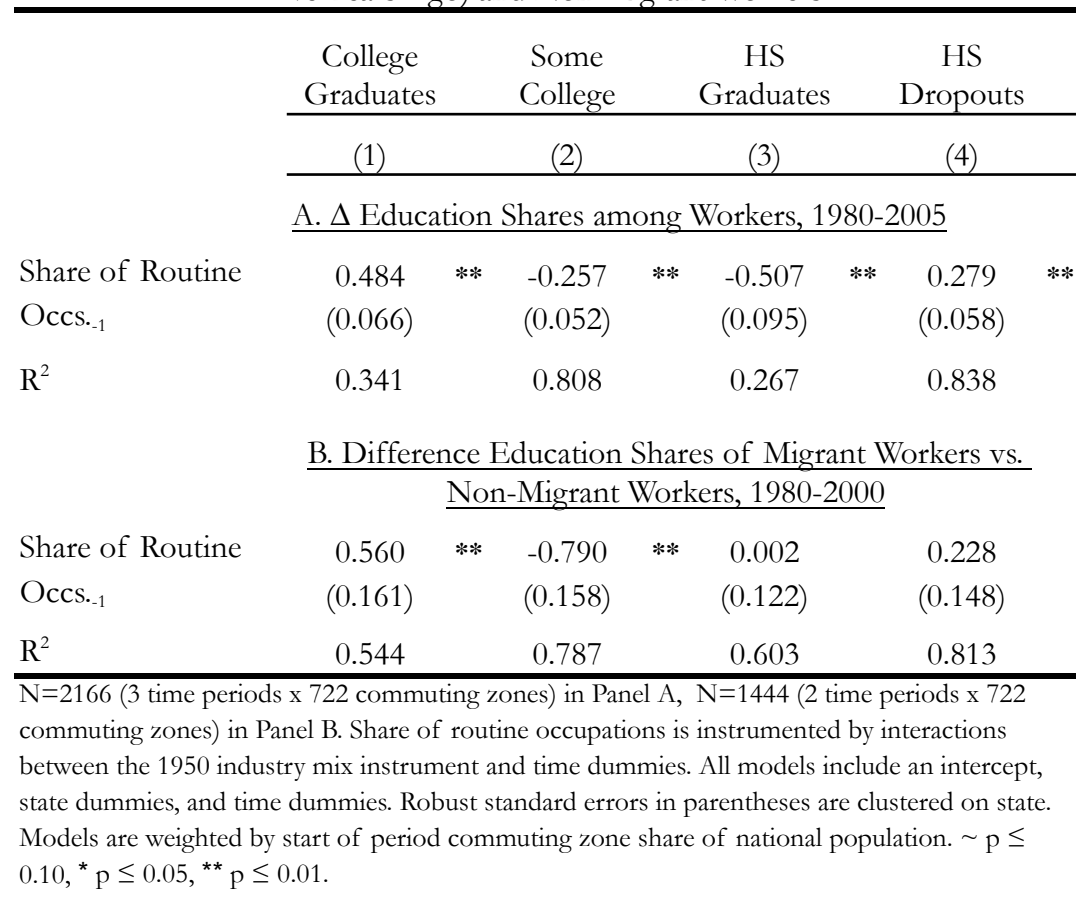




\section{Supplemental Theory Appendix for "The Growth of Low Skill Service Jobs and the Polarization of the U.S. Labor Market"}

\section{The planner's problem}

Given $p_{k}(t)$ at time $t$, the social planner's problem at time $t$ is to solve:

$$
\begin{aligned}
& \max _{K, \eta}\left(C_{s}^{\frac{\sigma-1}{\sigma}}+C_{g}^{\frac{\sigma-1}{\sigma}}\right)^{\sigma /(\sigma-1)} \\
& \text { s.t. } C_{g}=Y_{g}-p_{k}(t) K \\
& \qquad C_{s}=Y_{s}=L_{m}=1-\exp \left(-\eta^{*}\right) \\
& \text { where } Y_{g}=L_{a}^{1-\beta} X^{\beta} \\
& \qquad \begin{array}{l}
X \equiv\left[\left(\alpha_{r} L_{r}\right)^{\mu}+\left(\alpha_{k} K\right)^{\mu}\right]^{1 / \mu} \\
L_{r}=\left(\eta^{*}+1\right) \exp \left(-\eta^{*}\right) \\
L_{a}=1,
\end{array}
\end{aligned}
$$

where we write $\sigma_{c}$ as $\sigma$ to simplify notation. The above problem can further be simplified to:

$$
\begin{array}{ll} 
& \max _{K, L_{m}}\left(L_{m}^{\frac{\sigma-1}{\sigma}}+\left(Y_{g}-p_{k}(t) K\right)^{\frac{\sigma-1}{\sigma}}\right)^{\frac{\sigma}{\sigma-1}} \\
\text { where } \quad & Y_{g}=X^{\beta} \text { and } L_{r}=g\left(L_{m}\right) \equiv\left(1-\log \left(1-L_{m}\right)\right)\left(1-L_{m}\right),
\end{array}
$$

and $g(\cdot)$ is a function with the property that $g(0)=1$ and $g(1)=0$. Note that the social planner essentially chooses the level of capital, $K(t)$, and the allocation of labor $L_{m}(t)$ to manual tasks in the service sector (and thus, also the allocation $L_{r}(t)=g\left(L_{m}(t)\right)$ to routine tasks in the goods sector).

We next characterize the solution to problem (24). The first order conditions with respect to capital $K$ and labor $L_{m}$ respectively give:

$$
\begin{aligned}
\frac{\partial Y_{g}}{\partial K} & =p_{k}(t) \\
L_{m}^{-1 / \sigma} & =\left(Y_{g}-p_{k} K\right)^{-1 / \sigma} \frac{\partial Y_{g}}{\partial X} \frac{\partial X}{\partial L_{r}}\left(-\log \left(1-L_{m}\right)\right),
\end{aligned}
$$

where we have used

$$
g^{\prime}\left(L_{m}\right)=\log \left(1-L_{m}\right)=-\eta^{*} .
$$

The system in $(25)$ - (26) contains two unknowns $\left(L_{m}, X\right)$ in two equations and uniquely solves for the equilibrium at any time $t$.

We next characterize the behavior of the solution. We first consider the asymptotic equilibrium as $t \rightarrow \infty$ (or equivalently, as $p_{k}(t) \rightarrow 0$ ). We then characterize the dynamics of this equilibrium. 


\section{Asymptotic allocation of labor}

Note that the intermediate good $X$ is produced with a CES production function with elasticity $\frac{1}{1-\mu}>1$ over the inputs $L_{r}$ and $K$. Bearing in mind that $L_{r}$ is bounded from above, it can be seen that equation (25) holds as $p_{k} \rightarrow 0$ only if $K \rightarrow \infty$. In other words, we have

$$
\lim _{t \rightarrow \infty} K(t)=\infty
$$

Since $L_{r}$ is bounded from above, and since $L_{r}$ and $K$ are gross substitutes in the production of $X$, the production of $X$ in the limit will be essentially determined by the capital level. Formally, we have

$$
\lim _{t \rightarrow \infty} X / \alpha_{k} K=1
$$

Let $x \sim y$ be a shorthand for the notation that $\lim _{t \rightarrow \infty} x / y=1$. Then, the previous limit expression can be written as

$$
X \sim \alpha_{k} K
$$

Using Eq. (25) and Eq. (26) respectively, we further have

$$
Y_{g} \sim\left(\alpha_{k} K\right)^{\beta} \text { and } p_{k} K \sim \beta\left(\alpha_{k} K\right)^{\beta}
$$

From these expressions, net output (consumption) satisfies

$$
C_{g}=Y_{g}-p_{k} K \sim \kappa_{1} K^{\beta}
$$

where we define $\kappa_{1} \equiv(1-\beta) \alpha_{k}^{\beta}$. Using the expressions in Eq. (26), it can be seen that the asymptotic manual labor choice $L_{m}^{*} \equiv \lim _{p_{k} \rightarrow 0} L_{m}\left(p_{k}\right)$ is the solution to:

$$
\left(L_{m}^{*}\right)^{-1 / \sigma}=\kappa_{1}^{-1 / \sigma} \kappa_{2} K^{\beta-\mu-\beta / \sigma} L_{r}^{\mu-1}\left(-\log \left(1-L_{m}^{*}\right)\right)
$$

where $L_{r}=g\left(L_{m}^{*}\right)$, and we define $\kappa_{2} \equiv \beta \alpha_{k}^{\beta-\mu} \alpha_{r}^{\mu}$.

Using this equation and Eq. (27), the asymptotic level of $L_{m}^{*}$ is uniquely solved as follows: ${ }^{60}$

$$
L_{m}^{*}=\left\{\begin{array}{cl}
1 & \text { if } \frac{1}{\sigma}>\frac{\beta-\mu}{\beta} \\
\bar{L}_{m} \in(0,1) & \text { if } \frac{1}{\sigma}=\frac{\beta-\mu}{\beta} \\
0 & \text { if } \frac{1}{\sigma}<\frac{\beta-\mu}{\beta}
\end{array}\right.
$$

\footnotetext{
${ }^{60}$ Here, $\bar{L}_{m}$ is the solution to the equation:

$$
\left(\bar{L}_{m}\right)^{-1 / \sigma}=\kappa_{1}^{-1 / \sigma} \kappa_{2} g\left(\bar{L}_{m}\right)^{\mu-1}\left(-\log \left(1-\bar{L}_{m}\right)\right) .
$$
}




\section{Dynamics of equilibrium in the aggregate economy case}

Recall that $L_{r}$ is bounded from above and $K$ limits to $\infty$ (cf. Eq. (27)). Hence, $\frac{L_{r}(t)}{K(t)}$ will be decreasing for sufficiently large $t$. Suppose that $p_{k}(0)$ is sufficiently small so that $\frac{L_{r}(t)}{K(t)}$ is decreasing for all $t$ (intuitively, use of machines relative to routine labor monotonically increases). Under this initial parameterization, the dynamics of the model are straightforward. Note that:

$$
\frac{X}{K}=\left[\alpha_{r}^{\mu}\left(\frac{L_{r}}{K}\right)^{\mu}+\alpha_{k}^{\mu}\right]^{1 / \mu}
$$

will be strictly decreasing and it will limit to $\alpha_{\kappa}$. Then, in summary, we have the following dynamics:

$$
X \sim \alpha_{k} K, \quad Y_{g} \sim \alpha_{k}^{\beta} K^{\beta}, \quad p_{k} K \sim \beta \alpha_{k}^{\beta} K^{\beta}, \text { and } C_{g} \sim \kappa_{1} K^{\beta}
$$

The dynamics of $L_{m}(t)$ can be obtained by using these expressions in Eq. (26).

\section{Asymptotic wages}

We normalize the price of the good $g$ to 1 at each time $t$. Factors are paid their marginal products. Hence,

$$
w_{a}=\frac{d Y_{g}}{d L_{a}}=(1-\beta) Y_{g} \sim \kappa_{1} K^{\beta},
$$

where the last line uses the dynamics in Eq. (33). Similarly, note that

$$
w_{r}=\frac{\partial Y_{g}}{\partial X} \frac{\partial X}{\partial L_{r}}=\beta X^{\beta-\mu} \alpha_{r}^{\mu} g\left(L_{m}\right)^{\mu-1} \sim \kappa_{2} K^{\beta-\mu} g\left(L_{m}\right)^{\mu-1}
$$

where we used $L_{r}=g\left(L_{m}\right) \cdot{ }^{61}$

Finally,

$$
w_{m}=p_{s}=\left(\frac{C_{s}}{C_{g}}\right)^{-1 / \sigma}=\left(L_{m}\right)^{-1 / \sigma} C_{g}^{1 / \sigma} \sim\left(L_{m}\right)^{-1 / \sigma} \kappa_{1}^{1 / \sigma} K^{\beta / \sigma} .
$$

\footnotetext{
${ }^{61}$ Note that, unlike $w_{a}$, the dynamic behavior of $w_{r}$ is not necessarily monotonic. In particular, Eq. (35) can also be written as

$$
w_{r}=\frac{\partial Y_{g}}{\partial K} \frac{\partial X / \partial L_{r}}{\partial X / \partial K}=p_{k} \frac{\alpha_{r}^{u}}{\alpha_{k}^{u}}\left(\frac{L_{r}}{K}\right)^{\mu-1} .
$$

The fact that $p_{k}$ is decreasing drives down $w_{r}$ because routine labor and machines are gross substitutes. On the other hand, $\frac{L_{r}}{K}$ is falling because of the increases in capital use. When $\mu<1$ (so that the inputs are not perfect substitutes), the increase in the use of the complementary factors (capital) also tends to push up the wages of routine labor. Hence, the dynamic path of routine wages might be non-monotonic.
} 


\section{Asymptotic wage ratios}

From these expressions, relative wages and their dynamics can be determined. We are most interested in $\frac{w_{m}}{w_{r}}$, the relative wage of low skill workers in goods versus services production. To obtain the asymptotics of this ratio, note that the first order condition (26) can also be written as:

$$
w_{m}=w_{r} \eta^{*}=w_{r}\left(-\log \left(1-L_{m}^{*}\right)\right)
$$

Then, using the characterization in (32), we have

$$
\frac{w_{m}}{w_{r}}=\left\{\begin{array}{c}
\infty \text { if } \frac{1}{\sigma}>\frac{\beta-\mu}{\beta} \\
-\log \left(1-L_{m}^{*}\right) \text { if } \frac{1}{\sigma}=\frac{\beta-\mu}{\beta} . \\
0 \text { if } \frac{1}{\sigma}<\frac{\beta-\mu}{\beta}
\end{array}\right.
$$

We are also interested in the behavior of the ratio $\frac{w_{a}}{w_{m}}$. Using equations (34) and (36), we have

$$
\frac{w_{a}}{w_{m}} \sim \frac{\kappa_{1} K^{\beta}}{\left(L_{m}\right)^{-1 / \sigma} \kappa_{1}^{1 / \sigma} K^{\beta / \sigma}} .
$$

If $\frac{1}{\sigma}>\frac{\beta-\mu}{\beta}$, then equation (38) shows that the asymptotic behavior of $\frac{w_{a}}{w_{m}}$ depends on $\sigma$. In particular,

$$
\frac{w_{a}}{w_{m}}=\left\{\begin{array}{l}
0 \text { if } \sigma<1 \\
1 \text { if } \sigma=1 \\
\infty \text { if } \sigma>1
\end{array}, \text { when } \frac{1}{\sigma}>\frac{\beta-\mu}{\beta}\right.
$$

If instead $\frac{1}{\sigma}<\frac{\beta-\mu}{\beta}$ (which is greater than 1), then Eq. (32) shows that $L_{m}^{*}=0$. But then, Eq. (38) shows that the ratio $\frac{w_{a}}{w_{m}}$ is indeterminate. This indeterminacy follows from a rather superficial reason. Although employment in the service sector limits to zero, the wages of the few remaining workers in this sector near the limit may be high. This suggests that the right object to consider may be the wage bill of manual labor. When we consider this object, we indeed have:

$$
\lim _{t \rightarrow \infty} \frac{L_{a} w_{a}}{L_{m} w_{m}} \sim \frac{\kappa_{1} K^{\beta}}{\left(L_{m}\right)^{1-1 / \sigma} \kappa_{1}^{1 / \sigma} K^{\beta / \sigma}}=0,
$$

where the last equality follows because $\sigma>1$ (so that $1-1 / \sigma>0$, and $\left(L_{m}\right)^{1-1 / \sigma}=0$ ).

Lastly, we derive the dynamics of the wage ratio between abstract and routine tasks. Eqs. (34) and (35) show that

$$
\lim _{t \rightarrow \infty} \frac{w_{a}}{w_{r}}=\frac{\kappa_{1} K^{\beta}}{\kappa_{2} K^{\beta-\mu} g\left(L_{m}\right)^{\mu-1}}=\frac{\kappa_{1} K^{\mu}}{\kappa_{2} g\left(L_{m}\right)^{\mu-1}}=\infty \text { when } \frac{1}{\sigma} \leq \frac{\beta-\mu}{\beta}
$$

where the last equality follows since $K \rightarrow \infty$, and since $L_{r}=g\left(L_{m}\right)>0$ when $\frac{1}{\sigma}<\frac{\beta-\mu}{\beta}$ (so that $g\left(L_{m}\right)^{\mu-1}$ is bounded from above). But the empirically relevant case corresponds to the parametric 
condition $\frac{1}{\sigma}>\frac{\beta-\mu}{\beta}$. In this case, the ratio $\frac{w_{a}}{w_{r}}$ does not necessarily limit to $\infty$, because $L_{r}=g\left(L_{m}\right)$ decreases to zero, and $g\left(L_{m}\right)^{\mu-1}$ might also limit to $\infty$ (it does so when $\mu<1$ ). Note, however, that in this case, the wages of routine labor are kept high for a reason analogous to above: routine tasks are not very important in production, and thus the economy allocates labor away from routine tasks; as there are very few workers remaining in routine tasks, each might be receiving a significant wage.

This intuition suggests that the routine sector overall should be receiving a lower wage payment, even though each routine worker might be receiving a high wage. In other words, the intuition suggests that we should instead attempt to prove the following:

$$
\lim _{t \rightarrow \infty} \frac{L_{a} w_{a}}{L_{r} w_{r}}=\infty \text { when } \frac{1}{\sigma}>\frac{\beta-\mu}{\beta} .
$$

That is, the share of abstract labor relative to the share of routine labor limits to infinity. To prove this, consider Eqs. (34) and (35) (and use $L_{r}=g\left(L_{m}\right)$ ) to get:

$$
\lim _{t \rightarrow \infty} \frac{L_{a} w_{a}}{L_{r} w_{r}}=\lim _{t \rightarrow \infty} \frac{\kappa_{1} K^{\beta}}{\kappa_{2} K^{\beta-\mu} g\left(L_{m}\right)^{\mu}}=\frac{\kappa_{1}}{\kappa_{2}}\left(\frac{K}{g\left(L_{m}\right)}\right)^{\mu}=\infty,
$$

where the last equality follows since $K$ increases but $g\left(L_{m}\right)$ is bounded from above. This proves the limit in (40), and completes our analysis for relative wages.

\section{Derivation of spatial equilibrium}

Let $\left\{L_{a, j}(t), L_{m, j}(t), K_{j}(t)\right\}$ and $\left\{w_{m, j}(t), w_{a, j}(t), w_{s, j}(t), p_{s}(t)\right\}$ denote the factor allocations and prices in region $j$ in the asymptotic equilibrium. As in the above static economy, we normalize the good price in each region to 1 , i.e., $p_{g, j}(t)=1$ for each $j$. Define also the ideal price index for the consumption aggregator, $\left(C_{s, j}^{\frac{\sigma-1}{\sigma}}+C_{g, j}^{\frac{\sigma-1}{\sigma}}\right)^{\sigma /(\sigma-1)}$, as

$$
P_{j}(t)=\left(p_{s, j}(t)^{1-\sigma}+1\right)^{1 /(1-\sigma)}
$$

Here, $P_{j}(t)$ is the cost of increasing the consumption aggregator by one unit. The spatial equilibrium condition in the high skill labor market can be written as

$$
L_{a, j}(t)>0 \text { only if } w_{a, j}(t) / P_{j}(t)=w_{a, j^{\max }}(t) / P_{j^{\max }}(t)
$$

A geographic equilibrium at time $t$ is a collection of factor allocations $\left\{L_{a, j}(t), L_{m, j}(t), K_{j}(t)\right\}$, and prices $\left\{w_{m, j}(t), w_{a, j}(t), w_{s, j}(t), p_{s, j}(t)\right\}$, such that two conditions hold:

1. Local market equilibrium: The allocations, $\left\{L_{a, j}(t), L_{m, j}(t), K_{j}(t)\right\}$, and prices, $\left\{w_{m, j}(t), w_{a, j}(t), w_{s, j}(t), p\right.$ 
constitute a static equilibrium of the region $j$ given high skill labor supply $L_{a, j}(t)$ and the price $p_{k}(t)$ (as described in the previous section).

2. Spatial equilibrium: The market for high skill labor is in spatial equilibrium when (42) holds for each region $j$, so that high skill workers have identical real earnings across all regions.

We conjecture that the asymptotic equilibrium allocations take the following form:

$$
\begin{aligned}
\frac{\dot{K}_{j}(t)}{K_{j}(t)} & =g_{K, j} \text { for some } g_{K, j}>0, \text { for each } j, \\
L_{m, j}(t) & \rightarrow 1, \\
L_{a, \bar{j}}(t) & \rightarrow L_{a} \equiv \sum_{j} L_{a, j} \text {.for one region } \bar{j} \text { (in particular, } g_{L, \bar{j}}=0 \text { ). } \\
\frac{\dot{L}_{a, j}(t)}{L_{a, j}(t)} & =g_{L, j} \text { for some } g_{L, j}<0, \text { for each region } j \neq \bar{j} .
\end{aligned}
$$

The rationale behind this equilibrium conjecture is as follows: The conjecture that $K_{j}(t)$ grows in every region intuitively follows from the fact that $p_{K}(t) \rightarrow 0$. The conjecture that $K_{j}(t)$ grows at a constant rate follows from the analysis in the previous section, which shows that the production function is asymptotically Cobb-Douglas. The conjecture that $L_{m, j}(t) \rightarrow 1$ follows from the parametric assumption $\sigma=1$, which ensures that each region in isolation would allocate all low skill labor to manual tasks.

The last two conjectures rely on the observation that all other factor allocations asymptotically grow at the constant rate. This suggests that high skill labor also asymptotically grows at a constant rate. However, this is only possible if all high skill labor is eventually allocated to a single region, and the rest of the regions lose high skill labor at an asymptotically constant rate (it is also possible if high skill labor is asymptotically constant in all regions, but this case can be ruled out). The identity of the region, $\bar{j}$, along with the constant growth terms $\left\{g_{K, j}, g_{L, j}\right\}$, are yet to be determined. We also conjecture that

$$
g_{Y, j} \equiv g_{L, j}\left(1-\beta_{j}\right)+\beta_{j} g_{K, j}>0 \text { for each } j
$$

(which will be verified below), which ensures that $Y_{g, j}(t)$ and $C_{g, j}(t)$ asymptotically grow at a positive rate.

Under these conjectures, much of the discussion of the closed economy model also applies to each region in spatial equilibrium. In particular, it can be seen that

$$
\begin{aligned}
X_{j}(t) & \sim \alpha_{k} K_{j}(t) \\
p_{k}(t) K(t) & \sim \beta L_{a, j}(t)^{1-\beta}\left(\alpha_{k} K_{j}(t)\right)^{\beta} \\
C_{g, j}(t) & \sim \kappa_{1} L_{a, j}(t)^{1-\beta}\left(\alpha_{k} K_{j}(t)\right)^{\beta} .
\end{aligned}
$$

Moreover, $C_{g, j}(t)$ and $p_{k}(t) K(t)$ also grow at the constant rate $g_{Y, j}>0$ (defined in $\left.(44)\right)$. This 
also implies that $g_{K, j}=g_{Y, j}+\delta$. Plugging in the definition of (44), we can also solve for $g_{K, j}$ in terms of $g_{L, j}$ :

$$
g_{K, j}=g_{L, j}+\frac{\delta}{1-\beta_{j}} .
$$

This expression is intuitive. On the one hand, capital grows in response to the technological progress. On the other hand, capital growth is potentially slowed by the fact that high skill labor may be leaving a region (note that, under our conjecture, $g_{L, j}$ is negative for all regions but one).

Wages in each region may be calculated exactly as in the closed economy model. Thus we have:

$$
\begin{aligned}
w_{s, j}(t) & \sim \kappa_{1} L_{a, j}(t)^{-\beta_{j}} K(t)^{\beta_{j}} \\
w_{m, j}(t) & =\left(\frac{C_{g, j}(t)}{C_{s, j}(t)}\right)^{1 / \sigma} \sim \kappa_{1}^{1 / \sigma} L_{a, j}(t)^{\left(1-\beta_{j}\right) / \sigma} K_{j}(t)^{\beta_{j} / \sigma}, \\
w_{a, j}(t) & =\kappa_{1} L_{a, j}(t)^{-\beta_{j}} K_{j}(t)^{\beta_{j}} .
\end{aligned}
$$

Note that $w_{m, j}(t)$ grows at rate $g_{Y, j} / \sigma$. In particular $w_{m, j}(t) \rightarrow \infty$. Using this observation and $p_{s, j}(t)=w_{m, j}(t)$, Eq. (41) can be simplified to

$$
P_{j}(t) \sim w_{m, j}(t)^{1 / 2} \text { for each } j
$$

Moreover, under the conjecture in (43), the labor market equilibrium condition (42) will be satisfied with equality for each region. Substituting Eq. (48), the labor market equilibrium condition can be written as follows:

$$
\frac{w_{a, j}(t)}{w_{m, j}(t)^{1 / 2}} \sim \omega(t) \text { for each } j
$$

where $\omega(t)$ is a function that is independent of region $j$.

\section{Equilibrium mobility and wages of high skill labor}

The spatial equilibrium condition for the high skill labor market can be written as

$$
L_{a, j}(t)>0 \text { only if } w_{a, j}(t) / P_{j}(t)=w_{a, j \max }(t) / P_{j \max }(t)
$$

where

$$
P_{j}(t)=\left(p_{s, j}(t)^{1-\sigma}+1\right)^{1 /(1-\sigma)}
$$

is the cost of increasing the consumption aggregator in local labor market $j,\left(C_{s, j}^{\frac{\sigma-1}{\sigma}}+C_{g, j}^{\frac{\sigma-1}{\sigma}}\right)^{\sigma /(\sigma-1)}$, by one unit. ${ }^{62}$ Eq. (50) says that region $j$ will have non-zero abstract labor supply if its real wage for abstract tasks matches the real abstract wage in the region $j^{\max }$.

\footnotetext{
${ }^{62} \mathrm{As}$ in the above static economy, we normalize the goods price in each region to 1 , i.e., $p_{g, j}(t)=1$ for each $j$.
} 
There are two forces operating in equation (51) that influence the decision of high skill labor to migrate. First, an increase in the skilled wage $w_{a, j}(t)$ creates an incentive for high skill labor to migrate to region $j$. Second, an increase in local prices $P_{j}(t)$ creates an incentive for high skill labor to migrate away from region $j$. The equilibrium allocation of skilled labor balances these two forces, so that high skill workers have identical real earnings across all regions.

Using the expressions for wages in (47), the labor market equilibrium condition in (49) can be written as:

$$
\frac{\kappa_{1} L_{a, j}(t)^{-\beta_{j}} K_{j}(t)^{\beta_{j}}}{\kappa_{1}^{1 / 2} L_{a, j}(t)^{\left(1-\beta_{j}\right) / 2} K_{j}(t)^{\beta_{j} / 2}}=\omega(t) .
$$

where

$$
\lim _{t \rightarrow \infty} \frac{w_{a, j}(t)}{w_{m, j}(t)^{1 / 2}}=\omega(t) \text { for each } j
$$

and $\omega(t)$ is a function that is independent of region $j$. The term $K_{j}(t)^{\beta_{j}}$ in the numerator of this expression captures the positive effect of capital growth on the share of high skill labor (since the two factors are complements). The term $L_{a, j}(t)^{-\beta_{j}}$ in the numerator captures the effect of the scarcity of high skill labor on wages. The denominator of this expression captures the effect of the capital growth on the price of service goods: as the economy grows faster, services (which are produced by scarce factors) become more expensive, which has a negative effect on the welfare of a high skill worker. In equilibrium, labor flows across regions until these forces are in balance and equation (52) is satisfied for each $j$.

Using the conjectures that $K_{j}(t)$ and $L_{a, j}(t)$ grow (or shrink) at asymptotically constant rates, equation (52) holds only if:

$$
\beta_{j} \frac{g_{K, j}}{2}=\left(\frac{1-\beta_{j}}{2}+\beta_{j}\right) g_{L, j}+\eta \text { for each } j
$$

where $\eta$ is some constant. Recall that region $\bar{j}$ has asymptotically zero high skill labor growth (see the conjecture in (43)). Hence, considering the previous equation for region $\bar{j}$ gives $\eta=\beta_{j} \frac{\sigma-1}{\sigma} g_{K, \bar{j}}$, which implies

$$
\beta_{j} \frac{g_{K, j}}{2}-\beta_{\bar{j}} \frac{g_{K, \bar{j}}}{2}=\left(\frac{1-\beta_{j}}{2}+\beta_{j}\right) g_{L, j} \text { for each } j .
$$

Plugging in the expression (46) and solving for $g_{L, j}$ gives:

$$
g_{L, j}=\frac{\delta}{1-\beta_{j}}-\frac{\delta \beta_{\bar{j}}}{1-\beta_{\bar{j}}} \text { for each } j .
$$

Using Eq. (46), the growth rate of capital is also characterized as:

$$
g_{K, j}=\delta\left(\frac{\beta_{j}}{1-\beta_{j}}-\frac{\beta_{\bar{j}}}{1-\beta_{\bar{j}}}\right) \text { for each } j
$$


Note that the conjecture $g_{L, j}<0$ for each $j \neq \bar{j}$ holds only if $\beta_{j}<\beta_{\bar{j}}$ for each $j \neq \bar{j}$. This implies that $\bar{j}=j^{\max }$. In other words, high skill labor is attracted at a constant rate to the region with the greatest $\beta_{j}$, which is the region that benefits most from the declining price of computer capital. ${ }^{63}$

As skilled labor leaves other regions $j \neq \bar{j}$, the price of services decreases in these regions and the welfare of high skill workers increases. In equilibrium, the rate of skilled labor's departure from other regions ensures that in every period $t$, the remaining high skill workers are indifferent between their current geographic region and all alternatives. In the asymptotic equilibrium, all high skill labor is attracted to the region $\bar{j}=j^{\text {max }}$ with the highest $\beta_{j}$.

Eqs. (53) and (54) completely characterize the constant growth rates in (43). It can be checked that the constructed allocation is an equilibrium.

\footnotetext{
${ }^{63}$ To see the intuition for this equilibrium, consider a setting in which high skill labor is initially at a positive constant level in each region. Regions with greater $\beta_{j}$ will have faster growth of capital and goods consumption. With a unit elasticity of substitution between goods and services, this leads to a proportional effect on the price of services. Also because $\sigma=1$, the good $Y_{g}$ asymptotically has a positive share of the consumption aggregator, which implies that $P_{j}(t)=w_{m, j}(t)^{1 / 2}$ grows at a rate slower than $w_{m, j}(t)$. Hence, regions with greater $\beta_{j}$ have faster growth of $w_{a, j}(t)$ and identical growth of $w_{m, j}(t)$, and therefore faster growth of welfare for high skill labor, $w_{a, j}(t) / w_{m, j}(t)^{1 / 2}$. Moreover, welfare rises equivalently for low skill workers in high $\beta_{j}$ regions since productivity gains accrue proportionately to both skill groups given Cobb-Douglas preferences.
} 